\title{
The tetrapod Caerorhachis bairdi Holmes and Carroll from the Lower Carboniferous of Scotland
}

\author{
Marcello Ruta, Andrew R. Milner and Michael I. Coates
}

\begin{abstract}
The tetrapod Caerorhachis bairdi, probably from the Pendleian Limestone Coal Group in the Scottish Midland Valley, is rediagnosed and redescribed, and its affinities are discussed. Caerorachis was originally interpreted as a temnospondyl amphibian, based on characters that are now regarded as primitive for tetrapods, or of uncertain polarity. Several features of Caerorhachis (e.g. gastrocentrous vertebrae, curved trunk ribs, reduced dorsal iliac blade, L-shaped tarsal intermedium) are observed in certain primitive amniotes. In particular, Caerorhachis resembles 'anthracosaurs', generally considered to be among the most primitive of stem-group amniotes.

The phylogenetic position of Caerorhachis is considered in the light of recently published cladistic analyses of Palaeozoic tetrapods. Most analyses place Caerorhachis at the base of, or within, 'anthracosaurs'. When multiple, equally parsimonious solutions are found, its 'anthracosaur' affinities are shown in at least some trees, and are supported by several informative and, generally, highly consistent characters. Alternative phylogenetic placements (e.g. sister taxon to temnospondyls) are usually less well corroborated.

If the fundamental evolutionary split of most early tetrapods into stem-group lissamphibians (e.g. temnospondyls) and stem-group amniotes (e.g. 'anthracosaurs') is accepted, then the revised interpretation of Caerprhachis sheds light on near-ancestral conditions for Amniota.
\end{abstract}

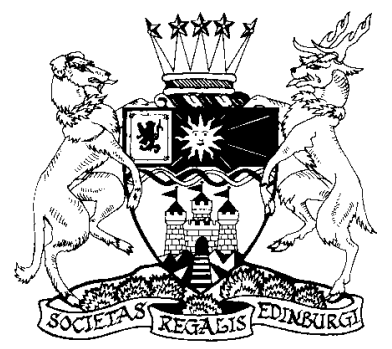

KEY WORDS: amniotes, 'anthracosaurs', characters, lower jaw, palate, relationships, skull.

In the present work, we reconstruct and redescribe Caerorhachis bairdi, one of the problematic fossil tetrapods '. . . fall[ing] into the nebulous area which surrounds the crown group node' (Ahlberg 1998, p. 104). Originally described by Holmes \& Carroll (1977), Caerorhachis was placed in the temnospondyls, a diverse group of Lower Carboniferous to Lower Cretaceous tetrapods often considered to be ancestral to some or all lissamphibians (e.g. Bolt 1979, 1991; Milner 1988, 1990; Milner \& Sequeira 1994). Several classifications of early tetrapods place Caerorhachis either in a basal position within temnospondyls, or as their plesiomorphic sister-taxon, sometimes in a monotypic family Caerorhachidae (e.g. Godfrey et al. 1987; Carroll 1998; Milner 1988, 1990, 1993a). This interpretation has been accepted by most workers until recently (e.g. Holmes 2000). However, some of the characters employed by Holmes \& Carroll (1977) to assign Caerorhachis to temnospondyls are broadly distributed among Palaeozoic tetrapods (e.g. radiating dermal sculpture), whereas others are of dubious polarity (e.g. rigid contact between skull roof and cheek) (Milner \& Sequiera 1994; Coates 1996; sections 5.1 and 5.2). A. R. Milner (1980) first suggested that hardly any anatomical feature of Caerorhachis can be regarded as a synapomorphy of this tetrapod with temnospondyls, apart from its rather small and narrow interpterygoid vacuities. In particular, the presence of large and horseshoe-shaped pleurocentra distinguishes Caerorhachis from even the most primitive temnospondyls (Milner \& Sequeira 1994, 1998). Milner \& Sequeira (1994) discussed Caerorhachis in the context of an analysis of character distribution in basal temnospondyls, and concluded that it should be removed from this group. According to Milner \& Sequeira (1994), Caerorhachis is best regarded as a tetrapod of uncertain affinities. However, they noted that its palate and internal nostrils are similar to those of baphetids (=loxommatids), an enigmatic clade of large Carboniferous tetrapods with keyhole-shaped orbits (Beaumont 1977; Beaumont \& Smithson 1998; Milner \& Lindsay 1998), variously regarded as stemgroup tetrapods (e.g. Milner et al. 1986; Ahlberg \& Milner 1994) or stem-group amniotes (e.g. Panchen \& Smithson 1988; Clack 1998a,b, in press). More recently, Coates (1996) hypothesised that Caerorhachis may represent a basal plesion in the amniote stem-group, as indicated by its gastrocentrous vertebrae, transverse pelvic ridge, and L-shaped tarsal intermedium. Indeed, various cranial and postcranial characters of Caerorhachis resemble morphological conditions found in several members of the 'anthracosaurs' (e.g. Holmes 1984, 1989; Panchen 1985; Smithson 1986, 1994; Clack 1987a,b, 1994, 1998a,b, 2001; Panchen \& Smithson 1987, 1988; Smithson et al. 1994; Lebedev \& Coates 1995; Coates 1996; Paton et al. 1999). 'Anthracosaurs', used throughout sensu Panchen \& Smithson (1988), include Permo-Carboniferous tetrapods placed by various authors among the most basal of stemgroup amniotes (e.g. embolomeres and gephyrostegids; see also Säve-Söderbergh 1934; Carroll 1970; Heaton 1980; Smithson 1986, 1994; Gauthier et al. 1988; Clack 1994, 1988a,b; Smithson et al. 1994; Coates 1996; Paton et al. 1999). In contrast, Laurin's (1998a-c), Laurin \& Reisz's (1997, 1999), and Laurin et al.'s (2000a,b) novel taxonomic use restricts the term 'anthracosaurs' to a clade including Solenodonsaurus, diadectomorphs and crown-group amniotes (but see comments in Coates et al. 2000).

Given such contrasting views on the affinities of Caerorhachis, a redescription is necessary in order to provide a more sharply defined picture of this taxon. Re-examination of Caerorhachis brings into focus some additional characters 
that complement its original description (Holmes \& Carroll 1977), and prompts a revised interpretation of several other characters. Recent advances in our understanding of early tetrapod comparative anatomy reveal the importance of this fossil: as in the case of the recently described Eucritta (Clack 1998b, 2001), Caerorhachis shows an interesting combination of plesiomorphies and apomorphies that may explain the conflict surrounding its interpretation. Therefore, a reappraisal of this animal may cast new light on morphological conditions occurring at the evolutionary split between different lineages of early tetrapods. This study examines only some aspects of the anatomy of Caerorhachis. Comparisons with other early tetrapods permit a revised interpretation of suture patterns and bone proportions on the skull roof and palate. A thorough redescription of the lower jaw is provided in the light of Ahlberg \& Clack's (1998) recent work on mandibular characters in early tetrapods. Several characters of the palate, mandible and postcranial skeleton that differ from those of temnospondyls are discussed in detail (e.g. spindle-shaped palatal vacuities, morphology of choanae, overall configuration of mandibular ramus, shape of basal plate of parasphenoid, gastrocentrous vertebrae, transverse pelvic ridge, etc.). New features of the pelvic girdle and hind-limb are highlighted (e.g. short dorsal iliac blade, pelvic sutures, acetabular shape, ischiotrochanteric tuberosity on femur, details of flexor surface of tibia, details of tarsal elements, etc.). Some characters of the axial skeleton and body armour not discussed by Holmes \& Carroll (1977) are mentioned briefly (e.g. haemal spine morphology, shape of gastralia, etc.). The atlas, axis, fore-limb and pectoral girdle do not require a redescription. The new reconstruction of Caerorhachis (Fig. 1A) differs in some respects from Holmes \& Carroll's (1977) (Fig. 1B). In particular, conservative estimates of lower jaw and presacral column lengths indicate that the head is more massive than previously assumed. Stout shape and relatively small size of the femur (compared with mandible length), and the very short tibia and fibula, contribute to the diminutive aspect of the hindlimbs. Incomplete remains of the fore-limb suggest that the latter, too, must have been rather small. The length ratios of head, trunk and tail are approximately $1: 2: 1+$. The total body length must have exceeded $200 \mathrm{~mm}$. The overall proportions are reminiscent of those of certain Australasian skinks, e.g. representatives of the genus Tiliqua (Pough et al. 2000).

In the analytical part of this paper, several recently published data matrices are used to test different hypotheses about the affinities of Caerorhachis with widely recognised and (mostly) well-characterised Palaeozoic groups. The rationale underlying our approach is that the systematic limits and content of major Palaeozoic groups are, with some exceptions, relatively simple to define (e.g. Panchen 1980; Smithson 1982; Hook 1983; Panchen \& Smithson 1987, 1988; Milner 1988, 1990, 1993a,b; Carroll 1995; Carroll et al. 1998; Milner \& Lindsay 1998). Therefore, it is possible to assess the characters of Caerorhachis against those considered to be apomorphous for various groups, regardless of the mutual placements of the latter in different cladograms. Conflicting phylogenetic positions for Caerorhachis (e.g. ambiguous placement in equally parsimonious trees or in trees deriving from different databases) can then be discussed in the light of reconstructed patterns of character distribution. Although not all the consulted databases provide unambiguous results with regard to the systematic interpretation of this animal (see 'Affinities' below), the 'anthracosaur' affinities indicated by some studies (e.g. Coates 1996; Paton et al. 1999) are linked to characters that are usually more consistent and, often, more numerous than those favouring alternative phylogenetic placements. In the case of Ahlberg \& Clack's (1998) lower jaw data set, Caerorhachis appears next to a paraphyletic 'anthracosaurs'. This placement may reflect either paucity of key features linking Caerorhachis unambiguously to other taxa, or the primitive nature of its lower jaws. Similar results are obtained by analysing Laurin's (1998a) matrix. However, manipulations of Ahlberg \& Clack's (1998) and Laurin's (1998a) data sets, based on taxon and/or character inclusion, place Caerorhachis within 'anthracosaurs' (see 'Affinities' below).

The Appendix includes the coding for Caerorhachis relative to seven recent analyses (Carroll 1995; Coates 1996; Ahlberg \& Clack 1998; Clack 1998a,b; Laurin 1998a; Paton et al. 1999; see Appendix). However, only four of these are discussed, namely Coates (1996), Ahlberg \& Clack (1998), Laurin (1998a), and Paton et al. (1999). These were chosen according to two criteria. First, Laurin's (1998a) and Paton et al.'s (1999) data sets supersede Carroll's (1995) and Clack's (1998a,b), respectively, in terms of character inclusion and taxon sampling. Therefore, they are likely to provide a more stringent test of the affinities of Caerorhachis. Second, Ahlberg \& Clack's (1998) and Laurin's (1998a) works offer a novel perspective on Palaeozoic tetrapod phylogeny, by placing most groups on the tetrapod stem. This perspective contrasts with the hypothesised deep evolutionary split of most Palaeozoic tetrapods into stem-group lissamphibians (e.g. temnospondyls) and stem-group amniotes (e.g. 'anthracosaurs'), as advocated by Coates (1996) and Paton et al. (1999). Investigation of conflicting solutions produced by different matrices falls outside the aims of this paper, and will be discussed elsewhere in conjunction with a new large-scale matrix for early tetrapods.

\section{Materials and methods}

Caerorhachis is preserved as acid-etched moulds of cranial and postcranial material, probably belonging to a single individual (Holmes \& Carroll 1977). Silastomer casts of different parts of the skeleton were measured (Table 1) and drawn using a Zeiss binocular microscope equipped with a camera lucida, and photographed under low-angle cross-lighting to enhance relief.

Consulted matrices were re-built in MacClade 3.0.5 (Maddison \& Maddison 1992), and re-processed with PAUP* 4.0b4a (Swofford 2000) on a PowerMac G4 under original weighting and ordering regimes. Search settings were as follows (see Swofford 1993 for explanations): heuristic random stepwise addition sequence (100 replicates; 10 trees held at each step); ACCTRAN optimisation; TBR algorithm; MULPARS and STEEPEST DESCENT options in effect. Basic tree statistics excluded uninformative characters. Changes in character weighting and/or ordering were considered in some analyses, and the resulting cladograms were compared with those of the original parsimony runs. With multiple solutions, we summarised cladogram information using strict consensus trees. Reweighting of character used the maximum (best fit) value of their rescaled consistency indexes. Branch support was evaluated using bootstrap and decay index. Bootstrap analyses (1000 replicates; groups compatible with 50\% majority-rule consensus), were performed via simple addition sequence (10 trees held at each step). However, time-consuming processing of Ahlberg \& Clack's (1998) and Laurin's (1998a) matrices forced us to employ a 'fast' stepwise addition option. For the same reason, decay values could not be calculated for those two matrices. Only scorable characters supporting the position of Caerorhachis were considered. A detailed breakdown of each analysis, including performance of all character state changes across all cladograms, is available upon request. 

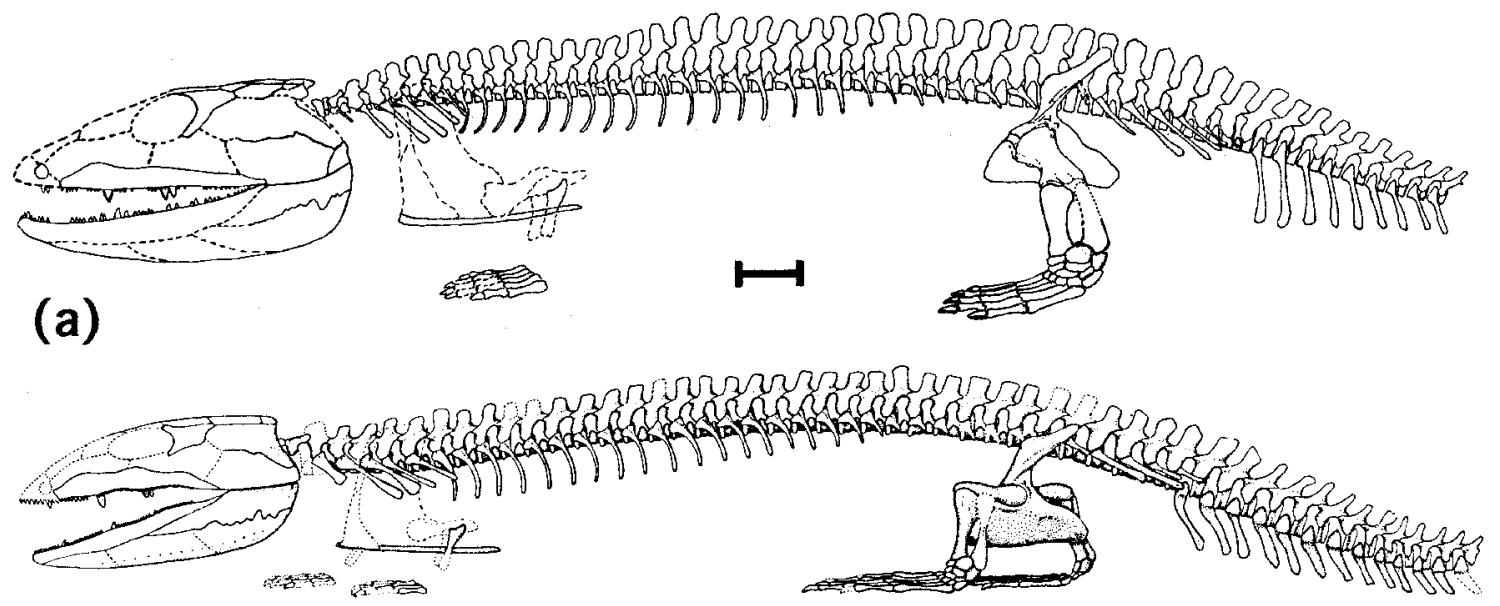

(b)
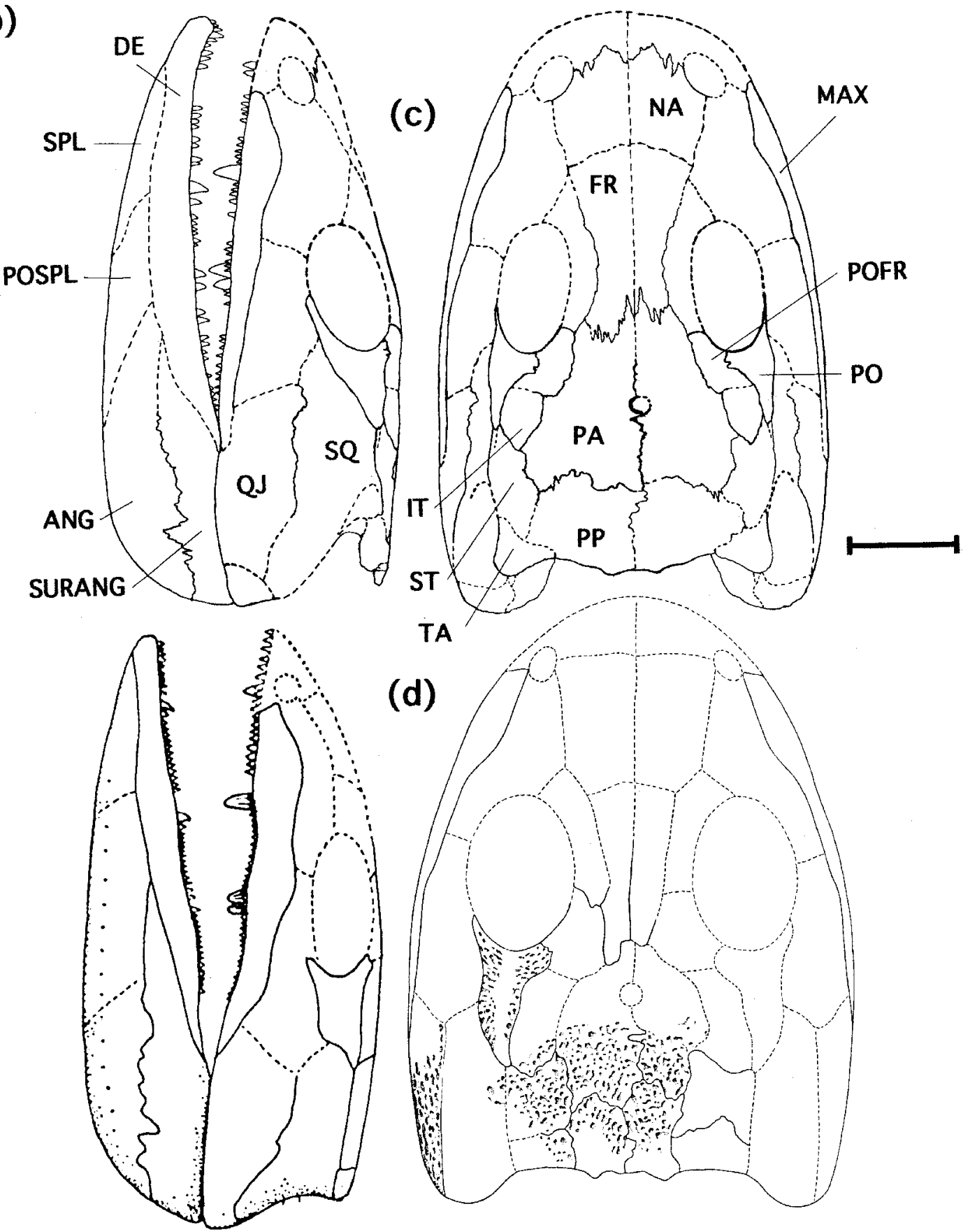

Figure 1 Caerorhachis bairdi Holmes \& Carroll: (a) revised reconstruction, and (b) Holmes \& Carroll's reconstruction of the skeleton, left lateral aspect and to the same length; (c) revised reconstruction, and (d) Holmes \& Carroll's reconstruction of skull, lateral and dorsal aspects and to the same length; scale bars $=1 \mathrm{~cm}$. 
Table 1 Anatomical measurements of Caerorhachis in mm.

\begin{tabular}{|lc|lc|}
\hline Length of lower jaw & 55 & Width of internal trochanter & 1 \\
Length of choana & 7 & Length of tibia & 12.5 \\
Length of puboischium & 24.7 & Length of longest metatarsal & 8.5 \\
Length of acetabulum & 6.5 & Height of best preserved pleurocentrum & 5 \\
Height of acetabulum & 6 & Width of best preserved pleurocentrum & 3.7 \\
Length of femur & 27 & Length of longest cervical rib & 14 \\
\hline
\end{tabular}

\section{Systematic palaeontology}

TETRAPODA Goodrich, 1930

Class, Order and Family unassigned

Genus Caerorhachis Holmes \& Carroll, 1977

Type species. Caerorhachis bairdi Holmes \& Carroll, 1977.

Diagnosis. As for the only species.

Caerorhachis bairdi Holmes \& Carroll, 1977

(Figs 1-15)

Holotype and only known specimen. MCZ 2271; Museum of Comparative Zoology, Harvard University. Incomplete individual on associated blocks of coal shale, sold to Harvard University in 1883 as part of the Thomas Stock collection of Scottish Carboniferous vertebrates. MCZ 2271 has no accompanying geographical or stratigraphical information, hence the use of question marks at the beginning of the following sections. According to Holmes \& Carroll (1977) and Smithson (1985a), the shale lithology is similar to that of the Loanhead No. 2 Ironstone, from which other specimens in the Stock collection have been recorded.

Locality. ?Ramsay colliery, Loanhead (Edinburgh), Midlothian, Scotland.

Horizon. ?Upper Limestone Coal Group; Loanhead No. 2 Ironstone (Holmes \& Carroll 1977); non Rumbles (Burghlee) Ironstone (Smithson 1985a), fide Andrews \& Brand (1991).

Age. ?Base of Serpukhovian, Pendleian Stage, Cravenoceras Zone (Harland et al. 1989).

Diagnosis (in the context of post-Devonian tetrapods; see also 'Remarks' below).

1. Presumed autapomorphies: subtrapezoidal tabulars with major axis at about $45^{\circ}$ to sagittal axis; toothless maxillary region at level of palatine fangs; subpentagonal choana; elongate anterodorsal process of posterior coronoid; densely denticulated mesial surface of lower jaw.

2. Synapomorphies (at various levels of taxonomic inclusiveness): broadly crescent-shaped postorbitals, slightly elongate anteroposteriorly, and about as large as supratemporals; narrow, spindle-shaped interpterygoid vacuities, less than half as wide as skull; absence of marginal teeth on ectopterygoids, palatines and vomers; rearward extension of parasphenoid; dorsomesial orientation of mandibular adductor fossa; absence of coronoid fangs and tooth rows; mesial laminae of infradentaries; small surangular crest; posterior coronoid with small, posterodorsal projection entering adductor fossa; fully ossified olecranon; boss-like internal trochanter separated from femoral head by trough-like space; interepipodial space between tibia and fibula.

Least ambiguous synapomorphies of Caerorhachis with stemgroup amniotes: subcircular depression on parasphenoid delimited by pronounced peripheral rim; enlarged U-shaped pleurocentra; reduced dorsal iliac blade; L-shaped tarsal intermedium.

Possible additional synapomorphies of Caerorhachis with stemgroup amniotes: rearmost part of mesial lamina of splenial closer to anterior margin of adductor fossa than to lower jaw symphysis; cervical ribs straight, morphologically distinct from trunk ribs and with flattened distal ends; curved trunk ribs; transverse ridge sweeping from lateral surface to ventral margin of posterior iliac process.

Possible synapomorphies of Caerorhachis with baphetids: elongate choana, slightly wider posteriorly than anteriorly, close to upper jaw margin, and with postero-mesial angle at anterior end of vomer/palatine suture; ?poorly pronounced lateral outgrowth of prefrontal.

3. Symplesiomorphies: intertemporal; supratemporal/postparietal suture; anteroposteriorly elongate subtemporal fossa; vomer and palatine fangs; radiating dermal ornament; large number of dentary teeth; parasymphysial plate with two fangs and scattered denticles; denticulated parasphenoid; uniformly denticulated palate; mobile basal articulation; crescent-shaped intercentra; length of trunk ribs less than twice the combined height of pleurocentrum and neural spine; dorsal iliac blade and posterodorsal iliac process; incipient distal reduction of femoral adductor blade; pentadactyl pes; gastralia.

4. Other characters of uncertain polarity: palatine/ectopterygoid fangs 3-4 times larger than vomerine fangs; high head/ trunk length ratio; high femur/puboischium length ratio.

\section{Description}

The material consists of a weathered skull roof partly preserved as an endocast; slightly disrupted palate; incomplete basal plate and remains of cultriform process of parasphenoid; almost complete maxillae in ventral and mesial views; flattened, but virtually complete mandibular rami; partially articulated vertebral column in left aspect, including some cervical, trunk and caudal ribs; proximal tail region with haemal spines; crushed left half of pelvic girdle; left femur in extensor view; left tibia and incomplete left fibula in flexor view; disarticulated left foot; incomplete interclavicle and plate of right clavicle; fragments of fore-limb; gastralia. 


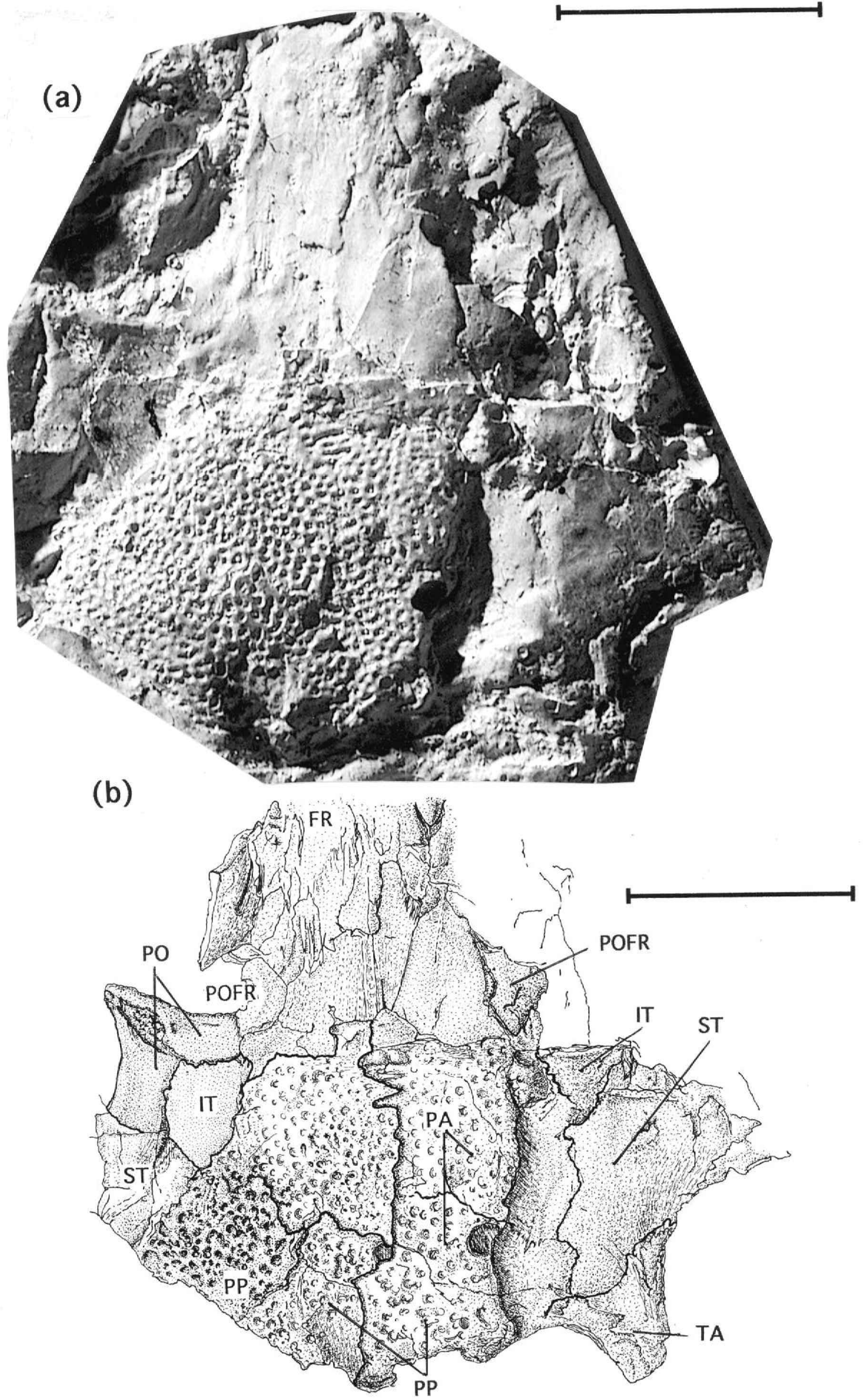

Figure 2 Caerorhachis bairdi Holmes \& Carroll: (a) MCZ 2271, incomplete skull table and endocast of preorbital region; (b) camera lucida drawing; scale bars $=1 \mathrm{~cm}$. 


\subsection{Skull table}

The incomplete skull table (Fig. 1C, D) is disrupted and mostly represented by an endocast (Fig. 2A). A posterior small area with dermal sculpture is visible. Holmes \& Carroll's (1977) interpretation of the latter is followed here, but we re-interpret a poorly preserved endocast surface immediately to the right of the sculptured area (Figs 1C, 2B). According to Holmes \& Carroll (1977), the surface in question includes the right supratemporal, tabular and squamosal (Fig. 1D). However, we suggest that the bone identified by them as the right supratemporal belongs in fact to the rightmost part of the right parietal. Anterolateral to this lies a small subtriangular area that may correspond to a weathered right intertemporal. A fragment of endocast, possibly belonging to the right postfrontal, is visible anteromesial to the right intertemporal. The area of endocast interpreted by Holmes \& Carroll (1977) as the right tabular is probably a continuation of the right postparietal, whereas the area corresponding to their right squamosal is considered to belong to the right supratemporal. The irregular suture between the right parietal and the right supratemporal contacts the anterolateral angle of the right postparietal. The course of the supratemporal/postparietal suture is poorly preserved.

Although the suture pattern at the back of the skull roof is temnospondyl-like (possibly primitive for tetrapods; Lombard \& Bolt 1995; Clack 1998a,b; Paton et al. 1999), it is important to note that the supratemporal/postparietal contact may reflect, at least in part, the configuration of the ventral side of the skull roof only. The spatial relationships of the supratemporal and postparietal on the ventral side do not always conform to the pattern observed on the dorsal side, as Smithson (1986) demonstrated in the case of Proterogyrinus pancheni. In this tetrapod, the dorsal side of the skull roof shows the typical tabular/ parietal contact found in all 'anthracosaurs'. Ventrally, these two bones are separated more or less completely by a narrow, strip-like, and anterolateral projection of the postparietal. In addition, the separation between tabular and parietal is complete on the right half of the ventral side, where the anterolateral projection of the postparietal forms a small suture with the supratemporal. On the left half, however, tabular and parietal retain a point contact. In Proterogyrinus scheelei (Holmes 1984) and Archeria crassidisca (Holmes 1989), the spatial relationships between tabular and parietal are identical on both sides of the skull roof, and this configuration is found also in other 'anthracosaurs'.

The crushed right tabular of Caerorhachis is visible posterior to the right supratemporal, from which it is delimited by a strongly sinuous and interdigitating suture, interpreted by Holmes \& Carroll (1977) as part of the posterior skull table margin. The tabular is subtrapezoidal, slightly larger than the intertemporal, and with a blunt posterior margin projecting slightly posterior to the postparietals. Its main axis is oblique to the sagittal axis. Unfortunately, its relationships with the postparietal are partly obscured by the poor preservation of its mesial portion.

The subrectangular parietals are almost twice as long as wide. Deep left and right indentations along the course of the irregularly sinuous interparietal suture indicate the probable position of the pineal foramen, although the latter is not clearly visible. In the absence of additional material, it is impossible to ascertain whether this condition reflects preservation or whether the pineal foramen underwent obliteration by ossification during ontogeny, as in medium- to large-sized specimens of the temnospondyls Cochleosaurus and Chenoprosopus (Milner $\&$ Sequeira 1998). Anterior to the sculptured area, the parietals are represented by partially weathered endocasts. Their anterior margins show irregular digitations, indicating rigid connection with the preorbital region. Incomplete endocasts of the frontals are visible anterior to such digitations, together with a weak trace of the interfrontal suture.

The subtrapezoidal postparietals resemble those of Crassigyrinus (Panchen 1985; Clack 1998a). Their posterior margins are slightly convex. However, we are uncertain about the occurrence of postparietal projections. These would correspond to small subtriangular areas near the posteromesial angle of each postparietal in Holmes \& Carroll's (1977) reconstruction, but their size may have been exaggerated by flattening.

The elongate, vaguely subtrapezoidal supratemporal endocasts appear almost featureless, and their margins are scarcely visible. Most of the left supratemporal is overlapped by two endocast fragments visible anterolateral to the left parietal. The larger fragment is undoubtedly a postorbital, based on its crescent-like shape and concave anterior margin. The smaller fragment, partly covering the postorbital, is likely to correspond to an anteromesially displaced left intertemporal. Its posterior two-thirds is approximately triangular and plectrum-shaped. Its poorly preserved anterior margin is gently concave.

A fragment of endocast lying just anterior to the anterolateral angle of the left parietal, a short distance away from the anterior margin of the left postorbital, deserves some comments. Its outline is poorly defined. It is divided into a broadly square posterior region, and an elongate, triangular region tapering rapidly anteriorly. Its overall shape suggests that it might represent either a postfrontal or a prefrontal, based on comparisons with such tetrapods as Balanerpeton or Eucritta (Milner \&. Sequeira 1994; Clack 1998b, 2001). It is difficult to ascertain whether this bone is preserved in its original orientation or has been rotated through $180^{\circ}$. If it is indeed a prefrontal preserved approximately in its original anatomical orientation, then the circumorbital series may reveal a pattern similar to that observed in baphetids (Beaumont 1977; Beaumont \& Smithson 1998; Milner \& Lindsay 1998). With the exception of Spathicephalus, all baphetids show pronounced outgrowths of the prefrontals and postorbitals or jugals. Such outgrowths delimit the boundary between orbits and antorbital vacuities, resulting in a characteristic, keyhole-shaped constriction of the combined orbit/antorbital vacuity. Assuming the correct identification and orientation of the prefrontal, the circumorbital bone pattern suggests the intriguing possibility that Caerorhachis possessed baphetid-like angular orbits. Given the poor preservation, this suggestion is extremely tentative and in our reconstruction (Fig. 1C), we have drawn more conventional, subelliptical orbits. Angular orbits, though not necessarily keyhole-shaped, are known in several other tetrapods, including Anthracosaurus (Panchen 1977; Clack 1987a), Crassigyrinus (Panchen 1973, 1985; Clack 1998a), and Whatcheeria (Lombard \& Bolt 1995).

The presence or absence of otic embayments cannot be securely determined. The lateral margin of the tabular may have contributed to a very shallow notch together with the posterior margin of the supratemporal, as in Loxomma or Eucritta (Beaumont 1977; Clack 1998b, 2001), but an accurate reconstruction of the temporal region is not possible, since both the tabular and the posterior part of the supratemporal are heavily eroded.

The postorbital and the incomplete quadratojugal and squamosal (Fig. 3A, B) were described by Holmes \& Carroll (1977), and will not be examined further. An endocast of the preorbital skull table is associated with the disrupted left half of the palate (Fig. 5A), but details of the bones are obscure. A broad nasal with an interdigitating anterior margin and shallow ventral grooves is visible distally (Fig. 5A). Similar grooves were observed by Clack (1987b) on the internal surface of the lacrimals and nasals in Pholiderpeton. 


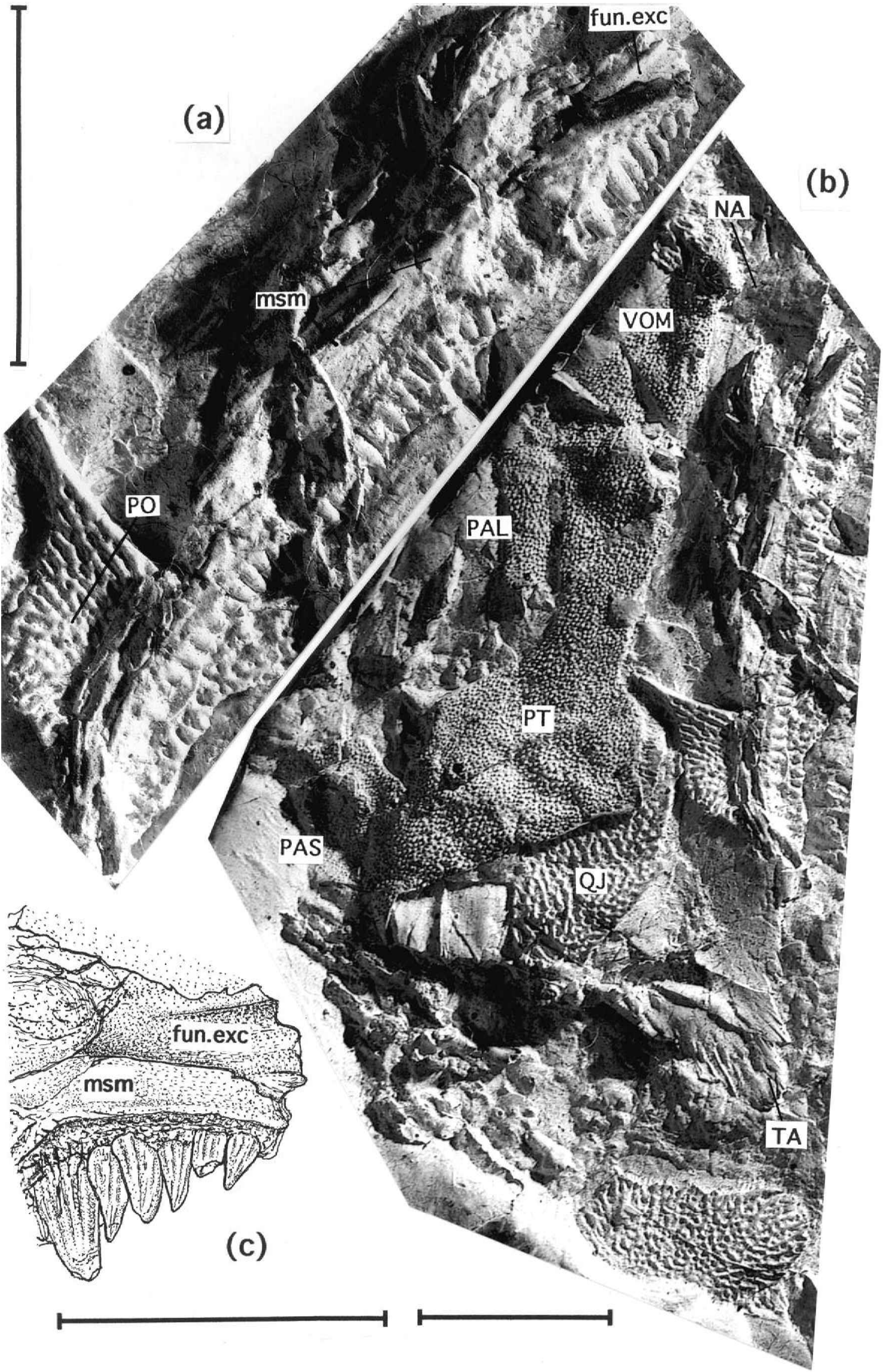

Figure 3 Caerorhachis bairdi Holmes \& Carroll: (a) MCZ 2271, mesial aspect of left maxilla, left postorbital in dorsal view; (b) MCZ 2271, incomplete left cheek and skull roof, disrupted endocast of preorbital region, mesial aspect of left maxilla, incomplete and disarticulated left half of palate, almost complete basal plate of parasphenoid, partially preserved atlas and axis; (c) camera lucida drawing of anterior end of left maxilla, showing funnel-shaped excavation (posterolateral wall of the choana); scale bars $=1 \mathrm{~cm}$ for (a, b); $0.5 \mathrm{~cm}$ for (c). 


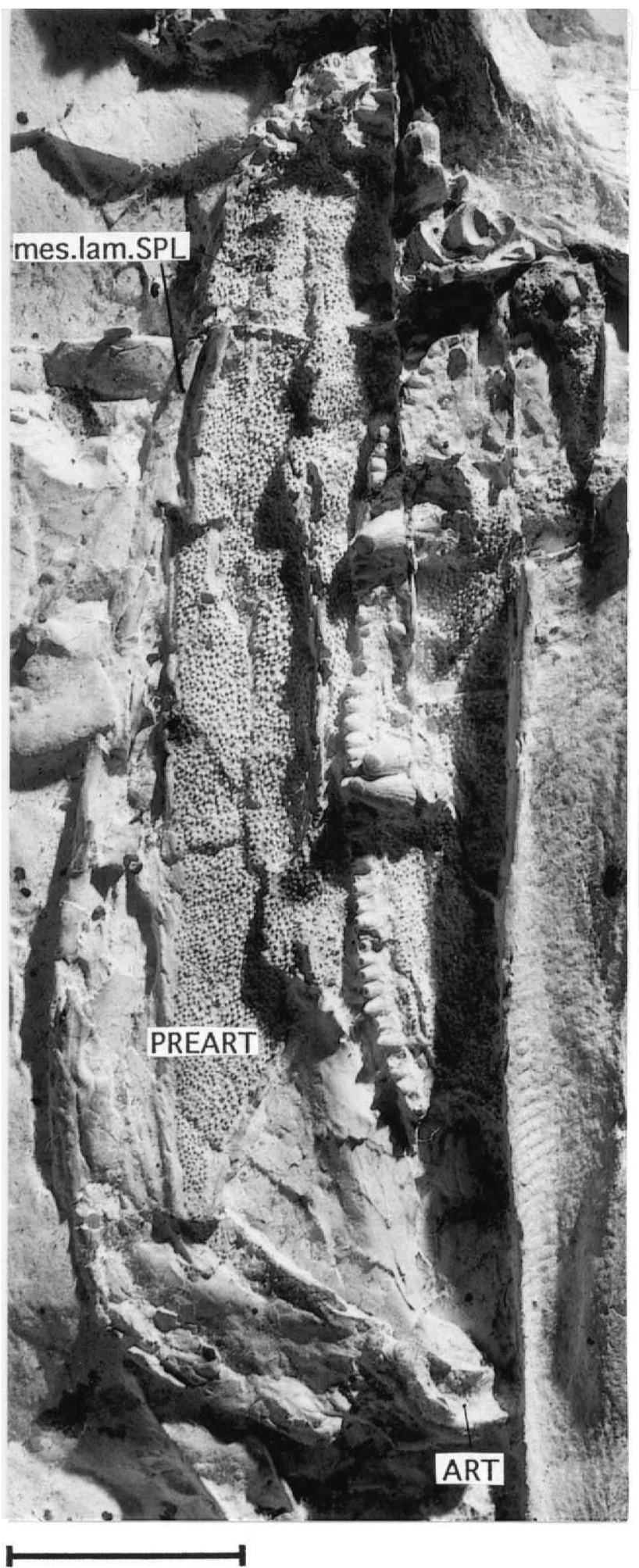

(a)
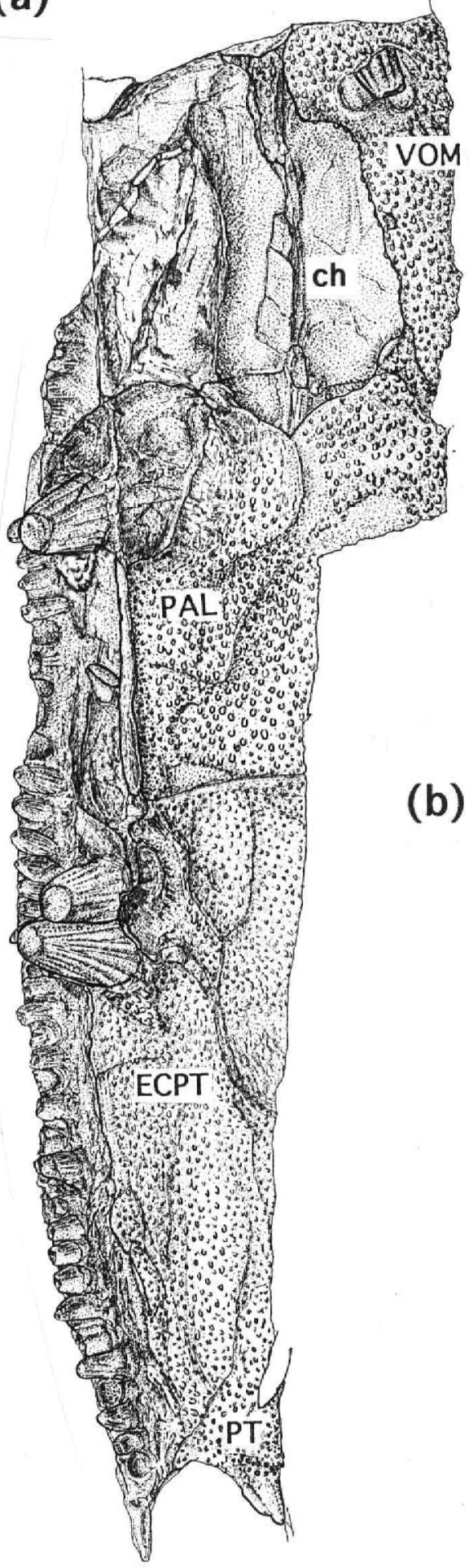

Figure 4 Caerorhachis bairdi Holmes \& Carroll: (a) MCZ 2271, incomplete right half of palate articulated with right maxilla, mesial aspect of right lower jaw ramus; (b) camera lucida drawing of right half of palate and right maxilla; scale bars $=1 \mathrm{~cm}$.

\subsection{Maxilla}

The maxilla (Figs 3A, 4, 5A), deeper in its anterior half than in its posterior half, carries a poorly developed mesial shelf (Fig. 5A). A gap in the tooth row, corresponding to the space normally occupied by about four or five tooth positions, is visible near the palatine fangs (Holmes \& Carroll 1977). The rostral end of the left maxilla shows a funnel-shaped excavation (posterolateral wall of the choana; Figs 3A, C, 5A), delimited dorsally by a sheet of bone with a distinct, rod-like mesial thickening, and ventrally by the anterior continuation of the mesial shelf The maxilla shows about 45 tooth positions. The maxillary teeth are comparable in size with the dentary teeth. The basal three-quarters of their crowns is cylindrical. Some maxillary teeth show an abrupt anticlockwise twist of their striations near the crown base.

\subsection{Palate}

Combined information from the two preserved portions of the 


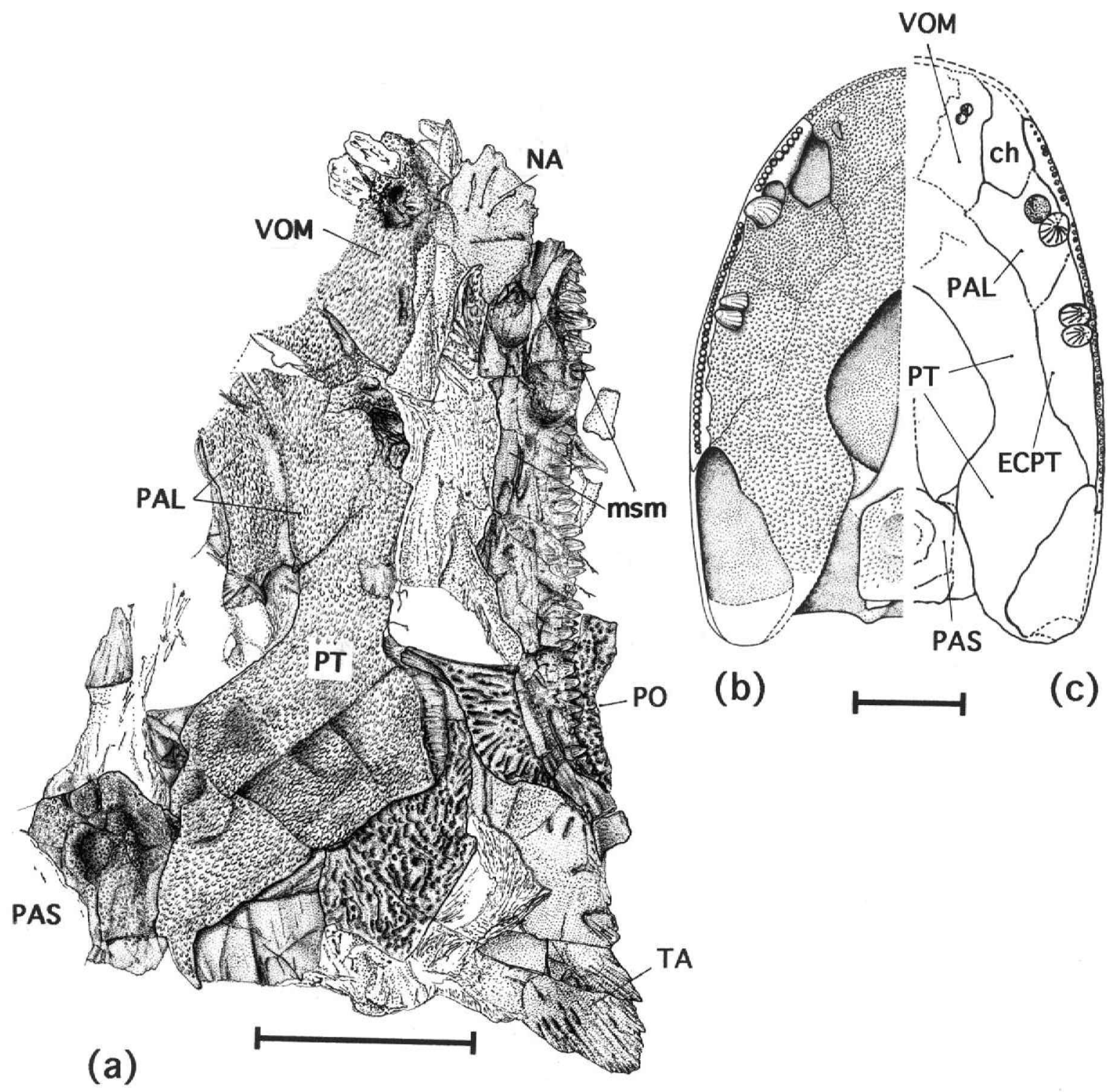

Figure 5 Caerorhachis bairdi Holmes \& Carroll: (a) camera lucida drawing of disarticulated left half of palate, left maxilla, basal plate of parasphenoid, and endocast of preorbital region; (b) Holmes \& Carroll's reconstruction of palate (anatomical right half); (c) revised reconstruction of palate (anatomical left half); denticle fields omitted; scale bars $=1 \mathrm{~cm}$.

palate (Figs 3B, 4, 5A) supports most of Holmes \& Carroll's (1977) reconstruction. Minor differences between our reconstruction (Fig. 5C) and theirs (Fig. 5B) concern the more anteriorly placed parasphenoid, the more oblique orientation of the palatine/ectopterygoid suture, and the position of the anterior extremity of the maxilla with respect to the anterolateral angle of the vomer. Despite lack of information concerning the shape and mesial extensions of the vomers and the morphology of the anteriormost part of the palatine rami of the pterygoids, the interchoanal region appears to have been rather broad, with contributions from both vomers and pterygoids. The relative proportions of vomers, palatines and ectopterygoids resemble those of baphetids (Beaumont 1977). Additional baphetid-like features include the overall shape of the choana (Figs 3B, 4, 5C), broader posteriorly than anteriorly, and the fact that the anterior end of the vomer/ palatine suture intersects the posteromesial angle of the choana (Figs 3B, 4, 5C). The inferred degree of curvature of the anterior snout margin (see also Holmes \& Carroll 1977) implies that the vomers are not likely to have shown an elongate prechoanal region, as found in cochleosaurids (Milner \& Sequeira 1998). The postchoanal extent of the vomers is uncertain, but an estimate of the position of their posterior margins indicates that these cannot have extended much posteriorly with respect to the level of the palatine fangs. If this was the case, then the anterior ends of the palatine rami of the pterygoids would display a unique, V-shaped configuration, not known in other tetrapods. Based on available evidence, it seems more likely that the pterygoids were wedged between the vomers, and that the intervomerine suture did not show a considerable backward projection with respect to the position of the choanae.

The interpterygoid vacuities are less than half as wide as the skull (Figs 3B, 5A, C). They differ from those of most temnospondyls in that they are not smoothly curved along their anterior, lateral and posterior margins (Romer \& Witter 1942; Romer 1947; A. R. Milner 1980; Milner \& Sequeira 1994; Schoch \& Milner 2000). The anterior half of the quadrate rami of the pterygoids (Figs 3B, 5A, C) is relatively broad and lacks a posterolateral flange. Such a flange confers a 
characteristic anterior constriction to the subtemporal fossa of many temnospondyls (Milner 1990; Yates \& Warren 2000), including the most primitive members of the group (Milner \& Sequeira 1994, 1998). In addition, the palatine rami of the pterygoids are quite broad, rather than strap-like as in several basal and derived temnospondyls.

Backward-pointing, strongly recumbent and striated denticles are uniformly distributed on the palate. They are smaller (about $0.06 \mathrm{~mm}$ diameter at the base) and more widely spaced on the posterior part of the quadrate rami of the pterygoids and near the anterolateral angles of the vomers. Small and irregular clusters of more robust denticles (about $0.17 \mathrm{~mm}$ in diameter at the base) lie mesial and anterior to the vomerine fangs. Similar clusters have been observed in other tetrapods (e.g. Tulerpeton; Lebedev \& Clack 1993). The palatal denticles reach the rearmost end of the quadrate rami of the pterygoids, as in Proterogyrinus (Holmes 1984). Several denticles appear broken or worn out. Details of the external surfaces of the smallest denticles are not discernible. However, as far as it can be determined, all denticles are striated, regardless of their size or position. An extensively denticulated palate also occurs in Devonian taxa (Jarvik 1980, 1996), some microsaurs (Carroll \& Gaskill 1978), 'anthracosaurs' (Carroll 1970; Holmes 1984), and several temnospondyls (Milner \& Sequeira 1994; Holmes et al. 1998).

\subsection{Lower jaw}

The essentially complete, albeit disrupted, lower jaw rami (Figs 4A, 6) are better preserved mesially than laterally. Their lateral surfaces, however, show the approximate position of the centres of radiation of dermal ornament on the dentary and infradentaries (Fig. 6A; see also Holmes \& Carroll 1977), as well as the partially preserved course of some sutures, especially those between dentary and surangular, and between dentary and splenial. The mesial aspect of the right ramus (Fig. 4A) provides most of the available information on the spatial relationships of coronoids and infradentaries, and on the shape of the adductor fossa. The left ramus (Fig. 6) shows the dentary and the symphysial region.

3.4.1. General shape. When reconstructed in mesial view (Fig. 7A), the lower jaw ramus is rather deep in its posterior half, and tapers uniformly anteriorly. Its ventral margin is more smoothly curved than in Holmes \& Carroll's (1977) reconstruction (Fig. 7B). The ramus does not carry a retroarticular process, and resembles in general proportions those of Crassigyrinus (Panchen 1973, 1985), Megalocephalus (Beaumont 1977) and various 'anthracosaurs' (Carroll 1970; Holmes 1984, 1989; Clack 1987b, 1998a; Ahlberg \& Clack 1998) (see Fig. 8A-I, K-N for comparisons with selected lower jaw rami of other extinct tetrapods). Jaw depth was calculated from the reconstructed mesial aspect following the method outlined by Clack (1987b). Depth was measured as maximum length of a line perpendicular to one joining the anterior end of the adductor fossa and the back of the articular, and expressed as a percentage of total jaw length, the latter was measured along a line joining the symphysis and the back of the articular. The depth/length ratio (about 20.85\%) is approximately intermediate between those of Proterogyrinus $(19 \cdot 2 \%)$ and Neopteroplax (22.35\%) based on Clack's (1987b) measurements.

3.4.2. Adductor fossa. The dorsomesially facing adductor fossa (Figs 4A, 6B, 7A) occupies about $26 \%$ of total jaw length. Compaction and crushing of the fossa region are evident in both rami. In the right ramus, the fossa appears to be roughly triangular, with a distinct straight posterior margin running dorsoventrally and slightly obliquely, and an anteroventral margin with an irregularly sinuous shape. Close examination reveals, however, that the anteroventral margin of the fossa has been slightly folded and pushed inside the fossa itself, that its posterior margin has been slightly rotated dorsolaterally (away from the median plane), and that its dorsal margin has been crushed. When such deformations are taken into account, it is possible to restore in part the shape of the fossa. This is likely to have had a roughly elliptical outline in life, similar but not identical to that of the left fossa as preserved. The latter appears distorted, albeit to a lesser degree than its antimere. Extreme flattening has damaged its anterior margin and squashed its postero-central third. The original reconstruction of the fossa (Holmes \& Carroll 1977) was based largely on information from the left ramus. In the revised reconstruction, the ventral margin of the fossa is not uniformly concave, but shows a slight bend more or less halfway along its length. Such a bend is partly visible in the left ramus, where its curvature has been decreased by compaction, and in the right ramus, where crushing has exaggerated its curvature, and has resulted in the sharp, upward displacement of its posterior half. A more or less prominent bend along the lower margin of the fossa is also found (among others) in the lower jaws of Gephyrostegus and Eocaptorhinus (Carroll 1970; Heaton 1979), as reconstructed by Ahlberg \& Clack (1998), and in Archeria, as figured by Holmes (1989). However, in all these taxa the bend is situated posteriorly along the ventral margin of the fossa. Furthermore, Caerorhachis does not possess a mesially directed flange along the postero-ventral margin of the fossa, unlike Gephyrostegus, Archeria, some temnospondyls, nectrideans and seymouriamorphs (Ahlberg \& Clack 1998).

3.4.3. Surangular crest. The anterodorsal margin of the surangular forms a very slight crest (Figs 4A, 6B, 7A). This region of the lower jaw is intermediate morphologically between those of Megalocephalus and Crassigyrinus, in which a surangular crest is absent, and those of Archeria, Pholiderpeton and most temnospondyls, in which the crest forms a distinct, raised step (Fig. 8). Caerorhachis also differs from many 'higher' temnospondyls (sensu Yates \& Warren 2000), in that the posterior coronoid is appressed, for a short distance backward, to the mesial side of the surangular crest, and is not exposed laterally, unlike the posterior coronoid of Pholiderpeton (Clack 1987b), Archeria (Holmes 1989), many temnospondyls (Romer 1947; Milner 1990; Yates \& Warren 2000), and several seymouriamorphs (White 1939; Bystrow 1944; Klembara 1997) and amniotes S.S. (Romer 1956).

3.4.4. Backward extensions of dentary and posterior coronoid. In lateral aspect, the left jaw ramus shows the backward extent of the dentary (Fig. 6A). In dorsal aspect, the rear end of the dentary is subtriangular, and tapers rapidly to a point, contributing to the dorsal margin of the adductor fossa only to a small degree. Conversely, in several primitive tetrapods (e.g. Acanthostega, Ichthyostega, Ventastega, Metaxygnathus, Densignathus, Crassigyrinus), the dentary shows a substantial backward extension (Fig. 8) (Ahlberg \& Clack 1998; Daeschler 2000). Immediately mesial to the rearmost part of the dentary, and seemingly applied closely to it, is an irregular process of the posterior coronoid. The process projects further posteriorly along the anterodorsal margin of the adductor fossa, but less extensively than in Holmes \& Carroll's (1977) reconstruction. The recumbent $\mathrm{V}$-shaped posterior margin in their reconstruction is likely to represent a fracture running across the dorsal half of the mesial surface of the surangular in the left ramus. The actual posterior margin of the process extends as far back as the anterior quarter of the fossa, and is rather narrow (Fig. 7A). The process is twisted halfway along its greater axis. 

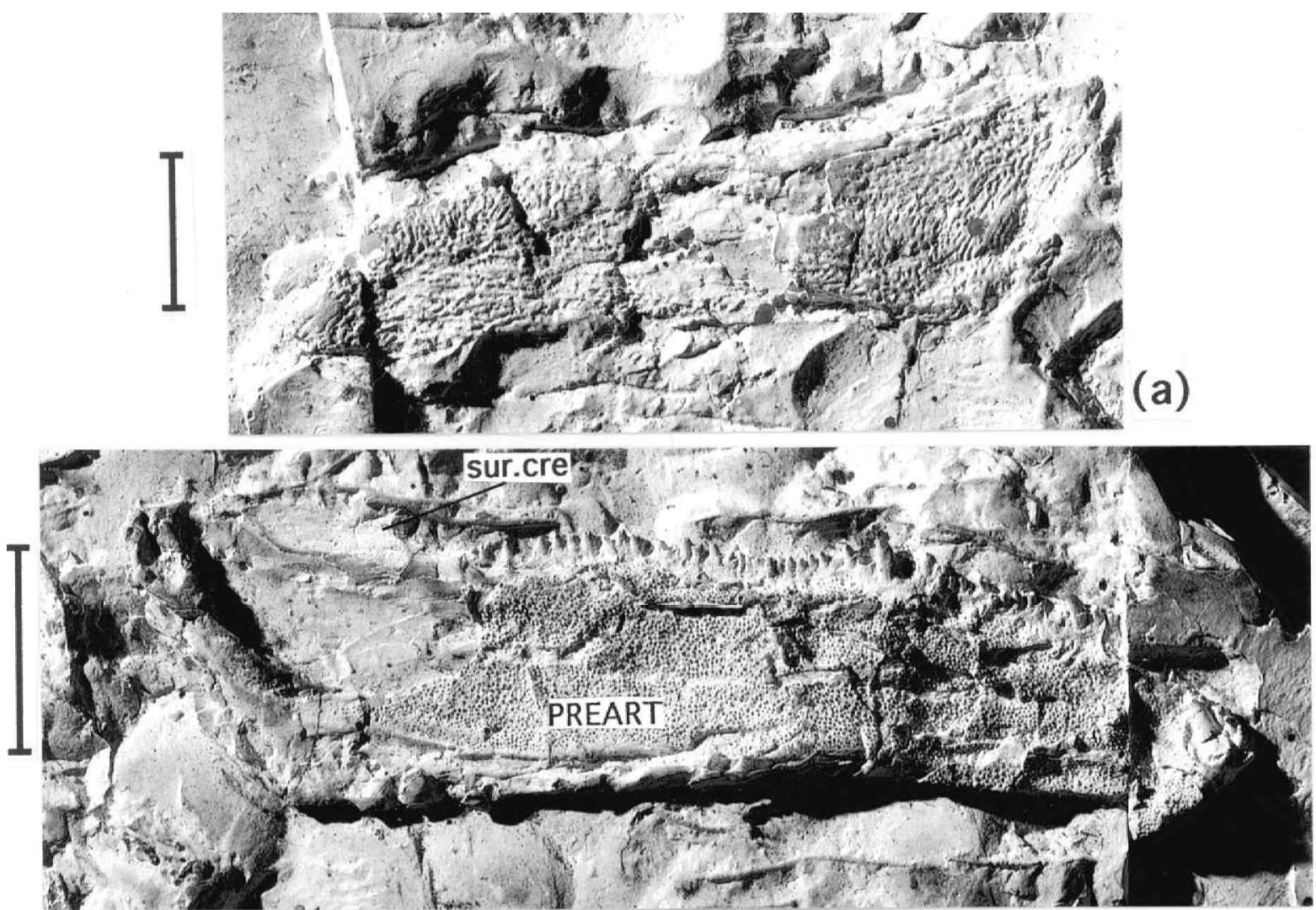

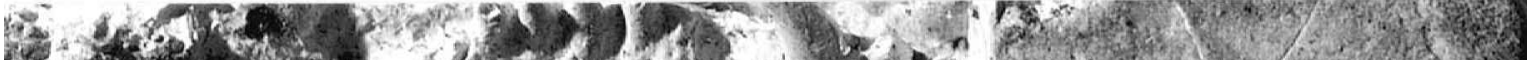

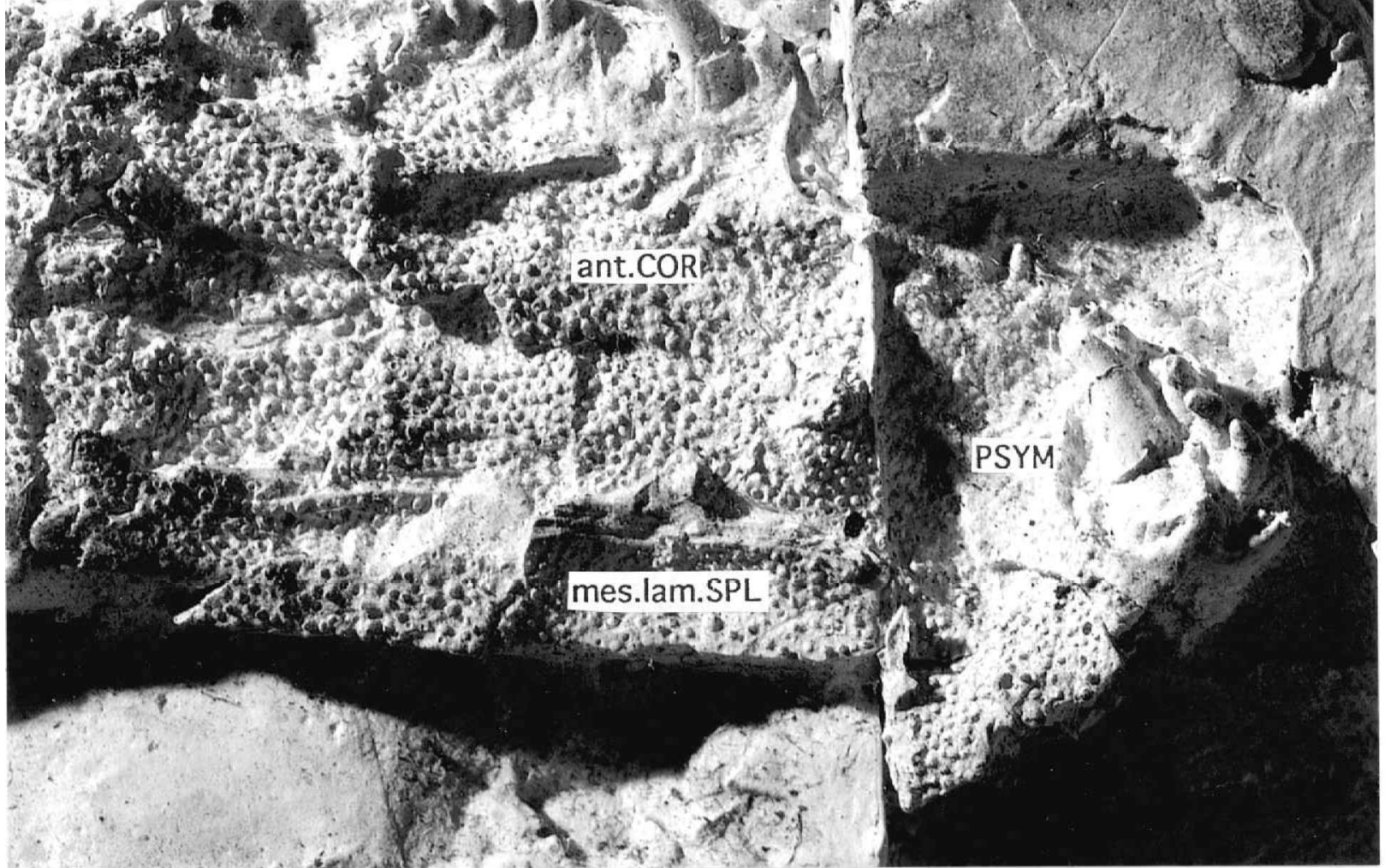

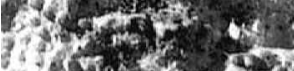

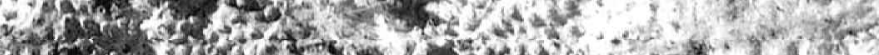

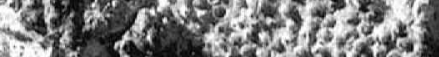

(c)

Figure 6 Caerorhachis bairdi Holmes \& Carroll: (a) MCZ 2271, left mandibular ramus, lateral aspect; (b) MCZ 2271, left mandibular ramus, mesial aspect; (c) MCZ 2271, close-up view of parasymphysial region of left mandibular ramus; scale bars $=1 \mathrm{~cm}$. 


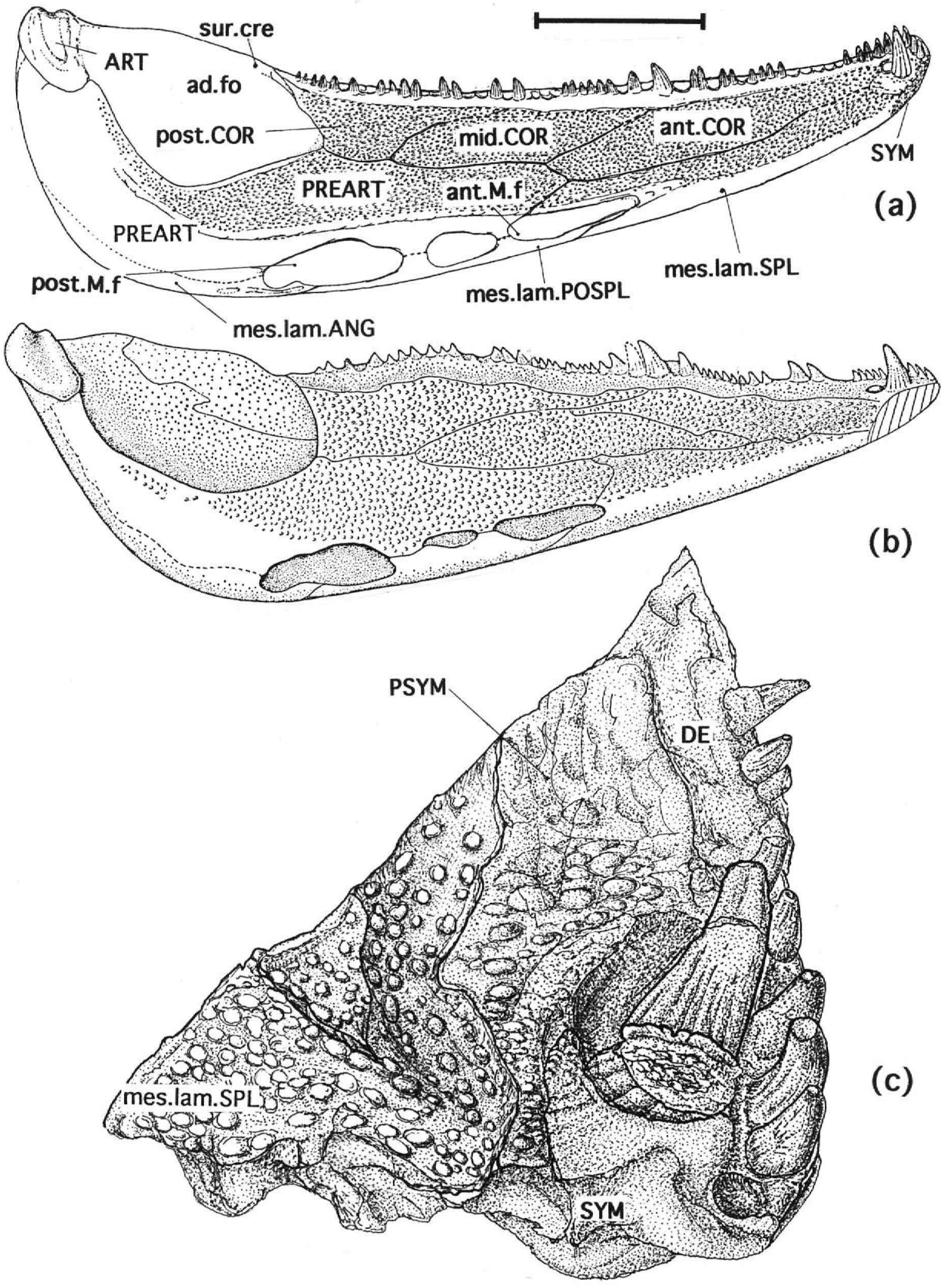

Figure 7 Caerorhachis bairdi Holmes \& Carroll: (a) revised reconstruction, and (b) Holmes \& Carroll's reconstruction of left mandibular ramus, mesial aspect; (c) camera lucida drawing of parasymphysial region of left mandibular ramus; scale bars $=1 \mathrm{~cm}$. 
(a)

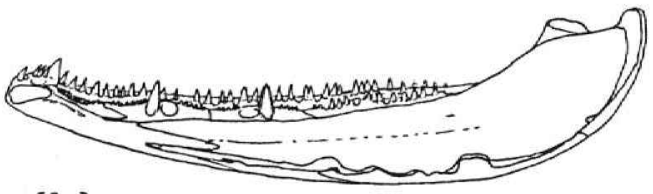

(h)
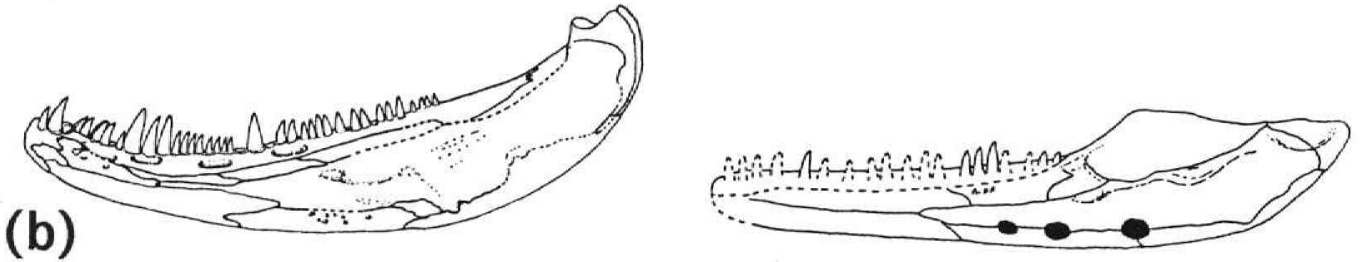

(i)
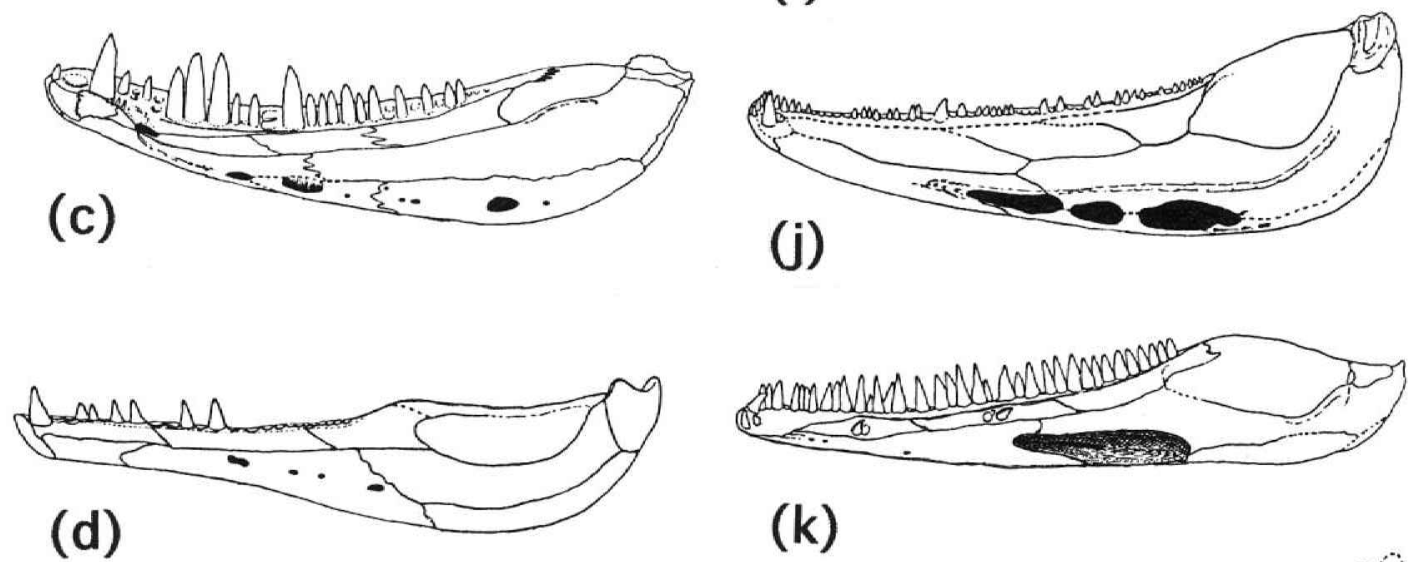

(k)
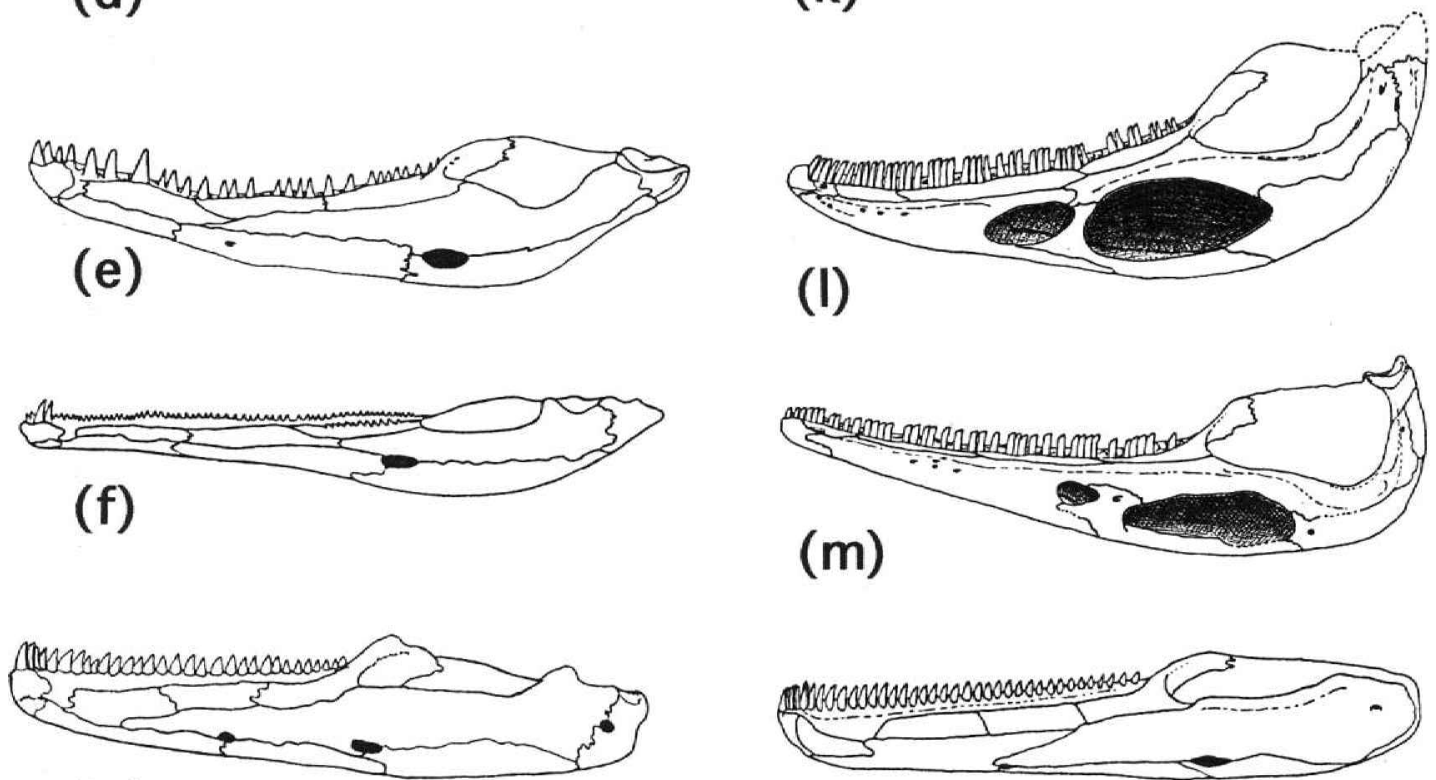

(g)

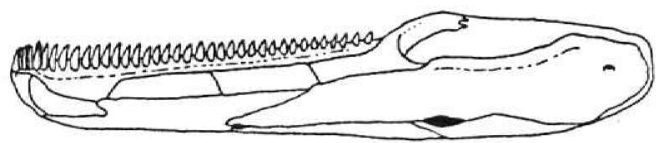

(n)

Figure 8 Reconstructions of right mandibular rami of early tetrapods, mesial aspect and to the same length; Meckelian foramina have been blackened; denticle fields, when present, have been omitted: (a) Acanthostega gunnari; (b) Crassigyrinus scoticus; (c) Megalocephalus pachycephalus (d) Balanerpeton woodi; (e) Eryops megacephalus, (f) Benthosuchus sushkini; (g) Kotlassia prima; (h) Ventastega curonica, (i) Eoherpeton watsoni; (j) Caerorhachis bairdi; (k) Gephyrostegus bohemicus; (1) Pholiderpeton scutigerum; (m) Archeria crassidisca; (n) Discosauriscus austriacus. Redrawn and modified from the following sources: a-c, h, k, Ahlberg \& Clack 1998; d, Milner \& Sequeira 1994; e, Romer 1947; f, Schoch \& Milner 2000; g, Bystrow 1944; i, Smithson 1985b; j, this paper; 1, Clack 1987b; m, Holmes 1989; n, Klembara 1997. 
3.4.5. Dorsal aspect and mesial extension of dentary. In lateral aspect (Fig. 6A), the dentary deepens uniformly in an anterior direction. In dorsal view, it widens abruptly at a point lying almost immediately anterior to the adductor fossa, and coinciding approximately with the position of the fifth or sixth most posterior tooth. More anteriorly, the width of the dentary is approximately constant, but it increases slightly just posterior to the parasymphysial plate (see below), at the level of the eighth or ninth most anterior tooth. The dorsolateral margin of the dentary forms a thin, subvertical wall, the mesial side of which covers about two-thirds of the height of the teeth on the posterior fifth of the dentary; and about half of the height of the remaining dentary teeth. The vertical wall decreases abruptly in height near the jaw symphysis. A few tooth sockets, visible along the length of the dentary, appear as labiolingually elongate depressions delimited by a poorly pronounced, peripheral rim. Below the rim, the mesial surface of the dentary is irregular, especially near the bases of the largest tooth crowns. Here, short and low thickenings that are obliterated rapidly in a mesial direction appear close to the sutures formed by the dentary with the coronoid series. The reconstruction of the mesial extension of the dentary is problematic. Disruption is especially evident in the right ramus, where the coronoids are folded mesially along their dorsal margins (Fig. 4A).

The dentary teeth (Figs 6B, 7A) are rather weak and relatively small compared with the size of the lower jaw. About 62 tooth positions are observed, with two position peaks, at the level of the $22 \mathrm{nd}$ and 36 th teeth approximately. The number of dentary teeth compares well with values recorded in such Devonian taxa as Acanthostega and Ventastega (Ahlberg \& Clack 1998), but is slightly larger than those observed in Pholiderpeton (Clack 1987b) and Archeria (Holmes 1989), and exceeds greatly those of Greererpeton (Smithson 1982), Crassigyrinus (Panchen 1973, 1985), Megalocephalus (Beaumont 1977), Proterogyrinus (Holmes 1984), Gephyrostegus (Carroll 1970), Ichthyostega (Jarvik 1980, 1996), early temnospondyls (Milner \& Sequeira 1994), all microsaurs, nectrideans and seymouriamorphs (Carroll \& Gaskill 1978; Klembara 1997; Bossy \& Milner 1998). The teeth of Caerorhachis are conical, slightly curved posteriorly and lingually, and taper smoothly near their blunt tips. Deep striations run along most of the crown height, but are usually very faint or absent on its upper third. The crowns are circular in crosssection, except near their bases, which are slightly elongate labiolingually.

3.4.6. Symphysial region. The new reconstruction of the symphysial region (Fig. 7A) differs from Holmes \& Carroll's (1977) (Fig. 7B) in showing a parasymphysial plate inserted between the anteriormost part of the mesial lamina of the splenial (mesially), the anteriormost part of the dentary (laterally) and the anterior coronoid (posteriorly) (Figs 4A, 6B, C, 7C). The hypothesised pattern of fractures on the left symphysial region of the jaw ramus matches almost perfectly that of the corresponding area on the right jaw ramus, thus casting doubt on the accidental nature of these 'fractures'. We believe them to represent parasymphysial plates. The parasymphysial plate carries two massive, slightly curved fangs lying mesial to the enlarged, anteriormost dentary teeth. In the left ramus, only one fang is visible, broken off one-quarter of the length of the crown above its base. The remaining part of the crown lies in close proximity, and is tilted backward, thus obscuring a shallow subcircular cavity lying behind the fang insertion. Such a cavity is likely to represent a replacement pit for a second fang. In the right ramus, a worn fang crown and a more posterior, broken crown are visible. The whole surface of the parasymphysial plate is covered with a scatter of small, posteriorly directed, irregularly distributed, and heavily worn denticles. The plate is approximately subtrapezoidal, but its lateral contact with the dentary is not clearly visible, due to the heavy disruption of the right ramus, and to the displacement of a parasymphysial fang in the left ramus. Mesially, the plate contacts a short anterodorsal portion of the mesial lamina of the splenial, whereas posteriorly, it is probably sutured with the anterior coronoid. The reconstruction of the symphysial region is based on the estimated forward extension of the anteriormost part of the coronoid, especially visible in the right ramus. The corresponding region of the left ramus is too fragmented to allow us to draw accurate comparisons with its counterpart. The ventral contribution of the anterior end of the dentary to the symphysial region cannot be ascertained.

3.4.7. Contributions of infradentaries to Meckelian foramina. In the anterior third of the jaw ramus, the mesial lamina of the splenial contributes to a large area of the mesial surface immediately behind the symphysial region (Figs 4A, 6B, C, 7A). The dorsal half of the mesial lamina of the splenial is extensively denticulated and is delimited from its smooth, lower half by a neat line. The mesial lamina of the splenial contributes to the anterior and dorsal margin of the anterior Meckelian foramen. Three small, subelliptical foramina are visible immediately anterior to the anterior Meckelian foramen. They occupy a shallow, anteroposteriorly elongate region just below the denticulated area of the mesial lamina of the splenial, and may correspond to similarly positioned, small foramina in Megalocephalus, Crassigyrinus, and Gephyrostegus (Ahlberg \& Clack 1998) (Fig. 8). The irregular suture between the mesial laminae of the splenial and postsplenial is visible below the anterior half of the ventral margin of the anterior Meckelian foramen. The suture runs initially very close to the ventral margin of the foramen before turning ventralward more posteriorly. The mesial lamina of the postsplenial contributes to the ventral margin of the mid Meckelian foramen and to most of the ventral margin of the posterior Meckelian foramen. At the level of the posterior Meckelian foramen, a short oblique line marks the posterior boundary of the mesial lamina of the postsplenial. The suture between the mesial lamina of the postsplenial and the prearticular is not clearly visible. A thin line running between the anterior and mid Meckelian foramina is tentatively interpreted as part of such a suture. Likewise, a disrupted line coming off the posterior margin of the posterior Meckelian foramen, and continuing irregularly posterodorsally, may represent the boundary between the mesial lamina of the angular and the prearticular. It becomes indistinguishable from the network of fractures visible behind the adductor fossa. It is, therefore, impossible to ascertain whether the dorsal part of the angular was wrapped around the posterior margin of the jaw ramus and exposed mesially. The area of the mesial lamina of the angular lying ventral to the posterior Meckelian foramen is occupied by a curved, elongate groove seemingly ending posteriorly in a foramen, and by two smaller elliptical foramina. Similar foramina are also observed in other taxa (e.g. Clack 1987b; Ahlberg \& Clack 1998).

3.4.8. Coronoid series and prearticular. As in several other Palaeozoic tetrapods, most of the mesial surface of the lower jaw is dominated by the coronoid series and the prearticular, and only to a limited extent by the infradentaries (Figs 4A, $6 \mathrm{~B}, \mathrm{C}, 7 \mathrm{~A})$. The mutual relationships of these bones resemble the morphological condition of Eoherpeton (Fig. 8). The two most remarkable features of the coronoids are the large size and great elongation of the anterior coronoid, and the fact that the posterior coronoid is relatively short and sends a 
long anterodorsal process wedged between the dentary and the middle coronoid. However, it is impossible to establish the precise outline of this process and its forward extension. Here, it is speculatively reconstructed as terminating a short distance behind the posterodorsal angle of the anterior coronoid, instead of extending forward to contact the latter, as in Holmes \& Carroll's (1977) reconstruction (Fig. 7B). All three coronoids lack teeth and fangs, but are extensively covered in tiny, backward-pointing, striated denticles. As in the case of the palatal denticles, striations occur regardless of the size and position of the denticles, although surface details of the crown are often obscured by poor preservation or breakage. The prearticular is more than half as long as the jaw ramus. Its mesial surface is divided neatly into a denticle-covered dorsal area and a smooth ventral area. The boundary between these two areas is marked by an elongate, low thickening with irregular margins, running from the posterodorsal margin of the anterior Meckelian foramen to a point situated just behind the sharp bend in the ventral margin of the adductor fossa. It then disappears almost abruptly in a posterodorsal direction. Irregular patches of less densely spaced, smaller denticles are visible along most of the length of the posterior margin of the adductor fossa. The wedge-like anterior end of the prearticular contacts the anterior and mid coronoids, dorsally, and the anterior coronoid and mesial lamina of the splenial, anteriorly.

The posterior extension of the denticles on the mesial surface of the lower jaw of Caerorhachis is a rather unusual feature. A comparable rearward extension has been recorded in very few tetrapods. Beaumont (1977, p. 71) described and reconstructed ' . . . an extension of the coronoid denticles forming a narrow band' along the posterior two-thirds of the dorsal margin of the prearticular in Megalocephalus. Such a band would extend posterodorsally to a point immediately below the articular. In contrast, Ahlberg \& Clack (1998, p. 33) ‘. . draw attention to the absence of shagreen on the coronoids or prearticular, and its replacement by fine but irregular pitting and sculpturing' on the mesial mandibular surface of Megalocephalus. Loxomma rankini likewise shows a scatter of posterodorsal denticles on the prearticular, not discussed by Beaumont (1977), but mentioned by Ahlberg \& Clack (1998). Outside tetrapods, an extensively denticulated prearticular occurs in various actinopterygians (e.g. Gardiner 1984) and sarcopterygians (e.g. Jarvik 1980; Fox et al. 1995; Long et al. 1997).

3.4.9. Articular. The articular (Figs 4A, 6B, 7A), about twice as wide as long, sits on top of the posterodorsal margin of the surangular, its mesial edge being slightly anterior and ventral to its lateral edge. In dorsal aspect, its outline is approximately bean-shaped, with thick, blunt-topped, anterior concave margin and posterior convex margin. Its mesial margin is bluntly convex and evenly round in dorsal view, whereas its lateral margin delimits a stout, roughly triangular process. The anterior and posterior margins delimit a trough-like condyle, strongly concave parasagittally, and gently convex transversely. In lateral aspect, there appears to be no distinct boundary between surangular and articular. In posterior and mesial views, a narrow groove is discernible below the ventral surface of the articular. Posterodorsal to it, the surangular sends a small, subtriangular lappet around the bowl-shaped base of the articular. The suture between the articular and the prearticular is not clearly identifiable. In mesial aspect, the posterodorsal region of the jaw ramus lying immediately below the articular probably represents the rearmost and dorsalmost part of the prearticular. It is difficult to ascertain to what extent the articular contributed to this region as well. A chorda tympani foramen could not be seen.

\subsection{Braincase}

The parasphenoid (Figs 3B, 5A, B) resembles those of Eucritta, Crassigyrinus, Whatcheeria, 'anthracosaurs', and some amniotes s.s. in showing a distinct central depression (Coates 1996; Clack 1998a,b 2001; Paton et al. 1999). It differs from the flat and, often, transversely expanded plate found in several temnospondyls. It is difficult to ascertain the presence of pronounced posterolateral basal tubera, such as those observed in 'anthracosaurs' (e.g. Clack 1987b; Holmes 1984, 1989), although these seem to have been absent. Only the most proximal part of the cultriform process is preserved. As a result, its forward extension and relationships with the vomers cannot be reconstructed. Possible basioccipital remains are represented by a rectangular fragment of bone covered in scattered denticles, visible behind the basal plate, and seemingly articulated with the latter. Although the basal plate is only partially preserved, its lateral margins and ventral surface do not show any traces of foramina for the internal carotid arteries. Yates \& Warren (2000) discussed four morphological conditions describing the position of the arteries with respect to the basal plate of the parasphenoid in various 'higher' temnospondyls. The absence of foramina in Caerorhachis suggests that the internal carotid arteries did not enter the parasphenoid through its ventral surface (foramina are present as a primitive condition in various 'higher' temnospondyls). As in some temnospondyls, the internal carotid arteries probably entered the parasphenoid from the dorsal surface without passing through ventral foramina on the plate. However, an alternative possibility is suggested by the occurrence of an anteroposteriorly elongate gap in the left half of the denticle-covered area of the basal plate (Figs 3B, $5 \mathrm{~A}, \mathrm{C})$, visible immediately behind the central circular depression. Clack (2001) interprets a similarly positioned gap in the basal plate of Eucritta as the pathway of the left internal carotid artery. The condition of Caerorhachis compares well with that of various 'higher' temnospondyls, except for the more posterior position of the carotid pathway (Schoch \& Milner 2000; Yates \& Warren 2000).

\subsection{Axial skeleton}

The vertebrae conform to, and are in several respects simpler (?more primitive) versions of, the gastrocentrous pattern exhibited by 'anthracosaurs'. The ossified portions of intercentra and pleurocentra (Figs 9, 10A, B) resemble more lightly built versions of those of Gephyrostegus (Carroll 1970), both in general proportions and in surface details, including sculpturing a extension of the articular surfaces. They are most similar to those of the early 'anthracosaurs' Silvanerpeton (Clack 1994) and Eldeceeon (Smithson 1994). Similarities with these taxa are also evident in the proportions of the trunk neural spines. These are square and stout, often only slightly taller than long in their upper half (above the zygapophyses level), and unlike the comparatively much taller spines of Proterogyrinus and Archeria (Holmes 1984, 1989). The irregular, almost jagged upper margin of some spines indicates that these were covered in a cartilage cap in life. The cervical ribs differ remarkably from the trunk and caudal ribs (Fig. 10C-E). They are straight, and carry flattened distal ends, a pattern observed, among others, in several basal and derived 'anthracosaurs' (Holmes 1984, 1989; Clack 1994; Smithson 1994; Smithson et al. 1994), some microsaurs (Carroll \& Gaskill 1978), and seymouriamorphs (White 1939; Berman et al. 2000). This morphological distinction was used by Coates (1996) to characterise a subset of the 'reptiliomorph' branch of his cladogram. The mid trunk ribs (Fig. 10D) are unlike those of 'anthracosaurs' (including such early forms as Eldeceeon and Silvanerpeton), in being comparatively much shorter, and exhibiting a more abrupt reduction in absolute size in an anteroposterior 


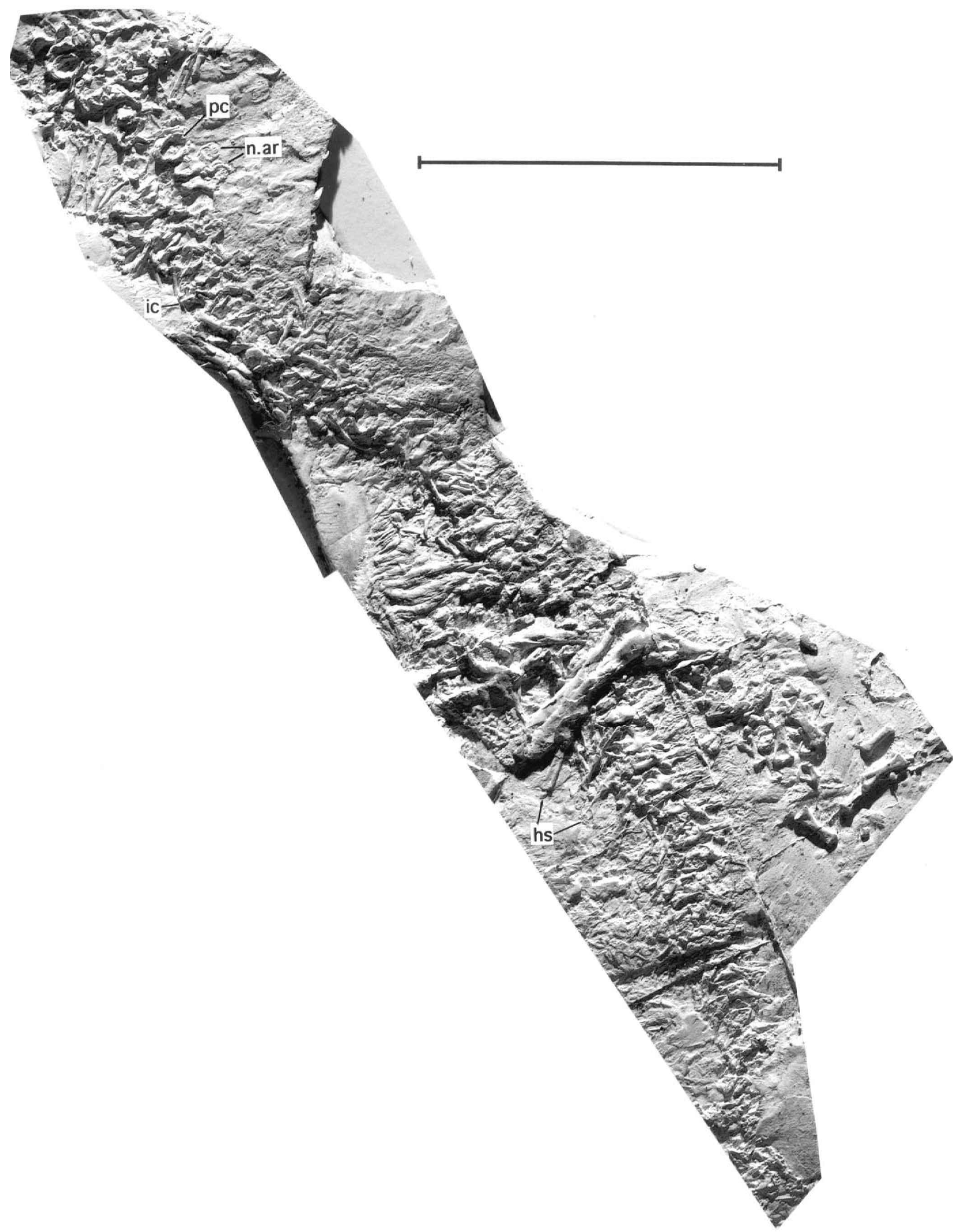

Figure 9 Caerorhachis bairdi Holmes \& Carroll, axial and appendicular skeleton of MCZ 2271; scale bar $=5 \mathrm{~cm}$. 


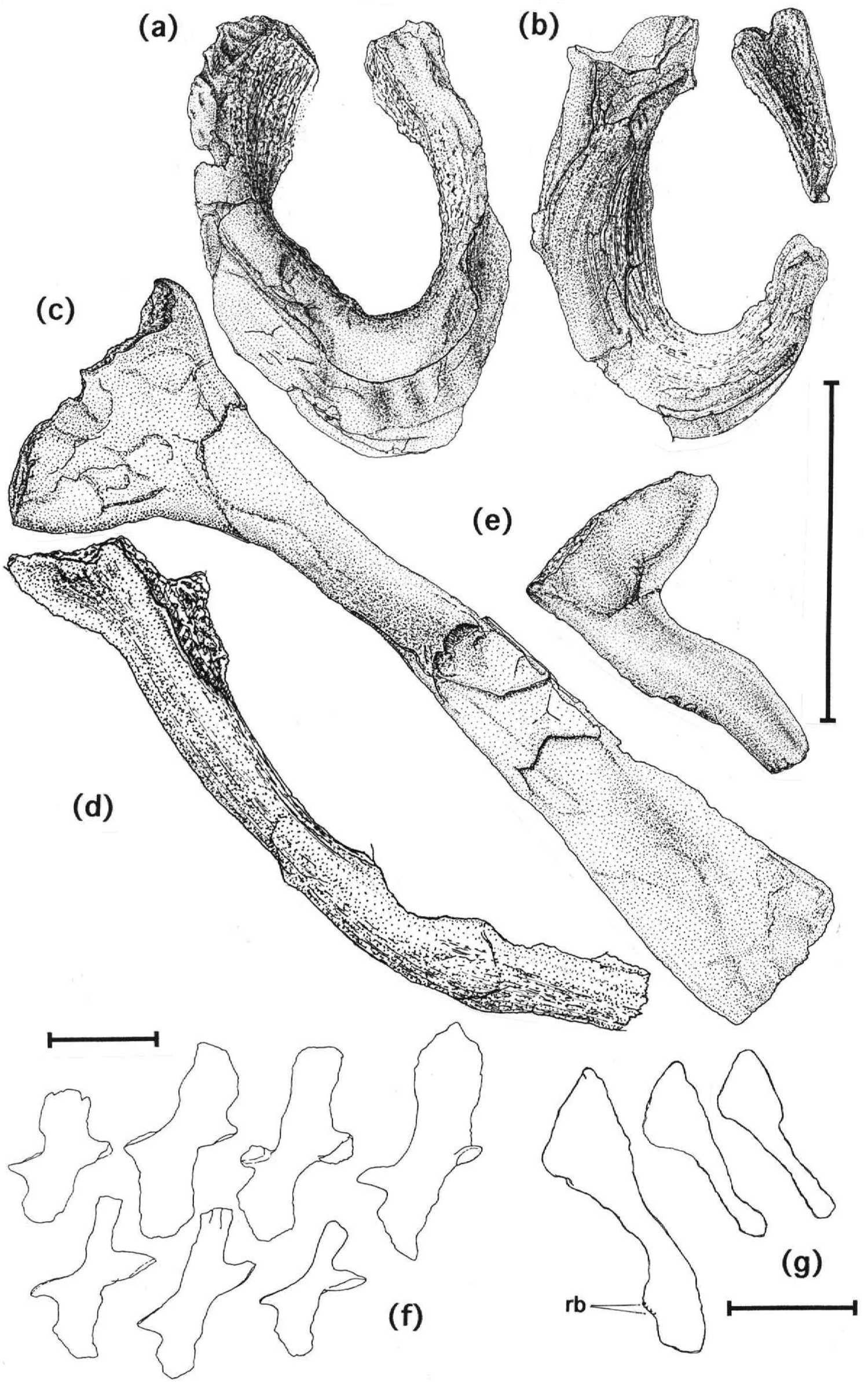

Figure 10 Caerorhachis bairdi Holmes \& Carroll: (a) pleurocentrum, anterior aspect; (b) pleurocentrum, posterior aspect; (c) left cervical rib, dorsal aspect; (d) left mid trunk rib, posterodorsal aspect; (e) left posterior trunk rib, dorsal aspect; (a-e) to the same scale; (f) neural spine outlines, left aspect and to the same scale; (g) haemal spine outlines, left aspect and to the same scale. All camera lucida drawings. Scale bars $=1 \mathrm{~cm}$ for $(\mathrm{a}-\mathrm{e}) ; 0.5 \mathrm{~cm}$ for (f, g). 
direction. Marked changes in neural spine morphology, as well as in the relative offsetting of pre- and postzygapophyses, are seen at three levels (Figs 1A, 9, 10F): between the anterior and posterior halves of the presacral column (corresponding to presacral 15 or 16 , approximately); between the posteriormost presacrals and the most anterior caudals; and between the most anterior caudals and the preserved portion of tail carrying haemal spines. Drastic height and length reduction of the most posterior caudal neural spines is also observed (corresponding to caudal 14 or 15 , approximately). The haemal spines (Figs 9, 10G) are comparable in relative size to those of the vast majority of 'anthracosaurs', except such early forms as Eldeceeon. In some of the better-preserved haemal spines, the ventral ends are foreturned and slightly expanded anteroventrally. The anterior margin of such an expanded end in one particularly well-preserved haemal spine carries minute, round bosses. However, preservation makes it difficult to ascertain whether these bosses are a genuine feature. They bear little resemblance to the heavily serrated anterior edge of the second haemal spine of Acanthostega (Coates 1996). The anteriormost haemal spine seems to have a flattened, subrectangular distal end. Likewise, the more posterior haemal spines terminate in a slightly spatulate end, but are less strongly foreturned than the more anterior spines. The rearmost preserved spines show no traces of a spatulate end.

\subsection{Appendicular skeleton}

3.7.1. Pelvic girdle. A few observations complement Holmes $\&$ Carroll's (1977) description (Fig. 11). Sutures between ilium, ischium and pubis are visible inside the acetabulum in the form of irregular grooves crossing the coarsely granular endochondral surface. They cannot be traced on the lateral surface of the girdle, except for a short tract of the ilium/ischium suture, visible posterior and slightly ventral to a short, tongue-like notch in the posterior part of the acetabular rim (see Coates 1996). Behind this notch, the iliac surface shows a deep, subcircular pit, below which is a slightly raised postacetabular buttress. Two small, round bosses and an irregular, elongate thickening are visible inside the pit. The significance of these structures is obscure; they may represent accidental bumps which occurred during the casting. The supracetabular buttress is robust, and carries a thick lateral margin. Anteroventrally, it merges into a poorly pronounced, anterior tongue-like notch. The ventral acetabular rim is produced into a semicircular lappet anteriorly, before merging into the unfinished, anterior margin of the pubis. The lappet, and the area of pubis lying just anteroventral to the acetabulum, are covered in short, irregular striations (?insertions for ambiens and/or pubotibialis muscles; see Romer 1922, 1956). The striations in the central area of the pubis are weaker than those on the lappet. A few, faint striations are also visible on the ischium, behind the acetabulum (?insertions for ischiotrochantericus muscle; Romer 1956). The proportions of the puboischium resemble closely those of Proterogyrinus and Archeria (Romer 1957; Holmes 1984, 1989). However, the relative size of the anterior and posterior tongue-like projections are more similar to those of Whatcheeria (Lombard \& Bolt 1995). A narrow area of endochondral bone is visible anterior to the main acetabular surface. It is delimited posteriorly by a small constriction of the acetabulum at the level of the ventral lappet and anterior tongue-like notch. No foramina are visible on the puboischium. However, details of its lateral surface are difficult to detect because of the dense network of fractures.

A remarkable feature of the ilium is the presence of a small, dorsal iliac blade (not discussed by Holmes \& Carroll 1977), regarded by Coates (1996) as a possible 'reptiliomorph' charac- ter. A thin sheet of bone extends from the dorsal iliac blade to the robust, straight posterodorsal process. Compaction makes it impossible to ascertain to which degree did the posterodorsal process lie lateral to the dorsal blade in life. Likewise, it is difficult to establish whether the dorsal process was unfinished anteriorly. A distinct transverse ridge (Romer 1922), interpreted by Coates (1996) as a possible apomorphy for basal amniotes, sweeps backward along a straight course from the lateral to the ventral surface of the posterodorsal process. We point out that a similar iliac ridge was also figured by Romer (1922) in Eryops (see 'Remarks' below), and by Holmes et al. (1998) in Dendrerpeton. An elongate, depressed area lies immediately dorsal to the ridge. Muscle insertions are visible in the form of irregularly sigmoid striations and crests across the depressed area and below the ridge. The iliac neck is rather robust compared with those of 'anthracosaurs', and is offset well posteriorly with respect to the supracetabular buttress (discussion in Coates 1996).

3.7.2. Hind-limb. The left femur (Fig. 12A) is preserved mainly in dorsal (extensor) aspect. Its shaft, head and adductor blade are slightly crushed, but its condylar region is almost intact, albeit flattened. Proximal and distal ends are only slightly wider than the shaft, which confers a rather massive aspect to the bone (see Fig. 12B-H, J-Y for comparisons with selected femora in other extinct tetrapods). Little torsion is evident around the longitudinal axis. The dorsal surface of the head is smoothly convex, more so than the shaft and the proximal part of the condylar region. The adductor blade projects anteriorly and slightly ventrally from the anterior surface, extending from a point situated slightly distal to the mid length of the shaft, to a point situated immediately distal to the transverse level of the femoral head. The dorsal surface of the blade is shallow near its insertion onto the shaft, but becomes flatter away from the latter, due to compaction. The distal half of the blade margin shows irregular denticulations, possibly resulting from disruption. The proximal apex of the blade ends in a stout boss-like internal trochanter, separated from the proximal end of the femur by a deeply incised trough, a condition observed in e.g. Tulerpeton (Lebedev \& Coates 1995), Crassigyrinus (Panchen \& Smithson 1990) and Archeria (Romer 1957; Holmes 1989). A small, elongate tuberosity on the posterodorsal surface of the femoral head, lying approximately at the same transverse level as the internal trochanter, may represent the ischiotrochantericus muscle insertion, based on a comparison with a similarly positioned structure in the femur of the synapsid Dimetrodon (Romer 1956). The anterodorsal region of the tibial condyle is covered by the proximal end of the left tibia, but it is possible to discern part of the seemingly bulbous tibial facet. Similarly, only the dorsalmost part of the fibular facet is visible. The visible part of the trough-shaped, distal surface of the intercondylar groove seems to have been made of finished bone, but its entire ventralward extension cannot be reconstructed. The tibial condyle is slightly shorter than the fibular condyle, and shows a more strongly convex dorsal surface, as is the case in most Palaeozoic tetrapods (Holmes 1984). The intercondylar groove is fairly distinct, deepens distally, and carries weak, irregular striations and rugosities, especially evident on the posterior surface of the tibial condyle. Two or three crescent-like ridges run transversely across the deeper part of the intercondylar groove. Small, irregular ridges also straddle the boundary between the tibial/fibular facets and their respective condyles, and are better developed on the distal part of the dorsal surface of the fibular condyle.

The stout left tibia (Fig. 13A, B) is less than half as long as the femur (40\% length ratio; Holmes \& Carroll 1977). A similar ratio characterises such tetrapods as Tulerpeton (Lebedey \& Coates 1995), Crassigyrinus (Panchen \& Smithson 1990), and 

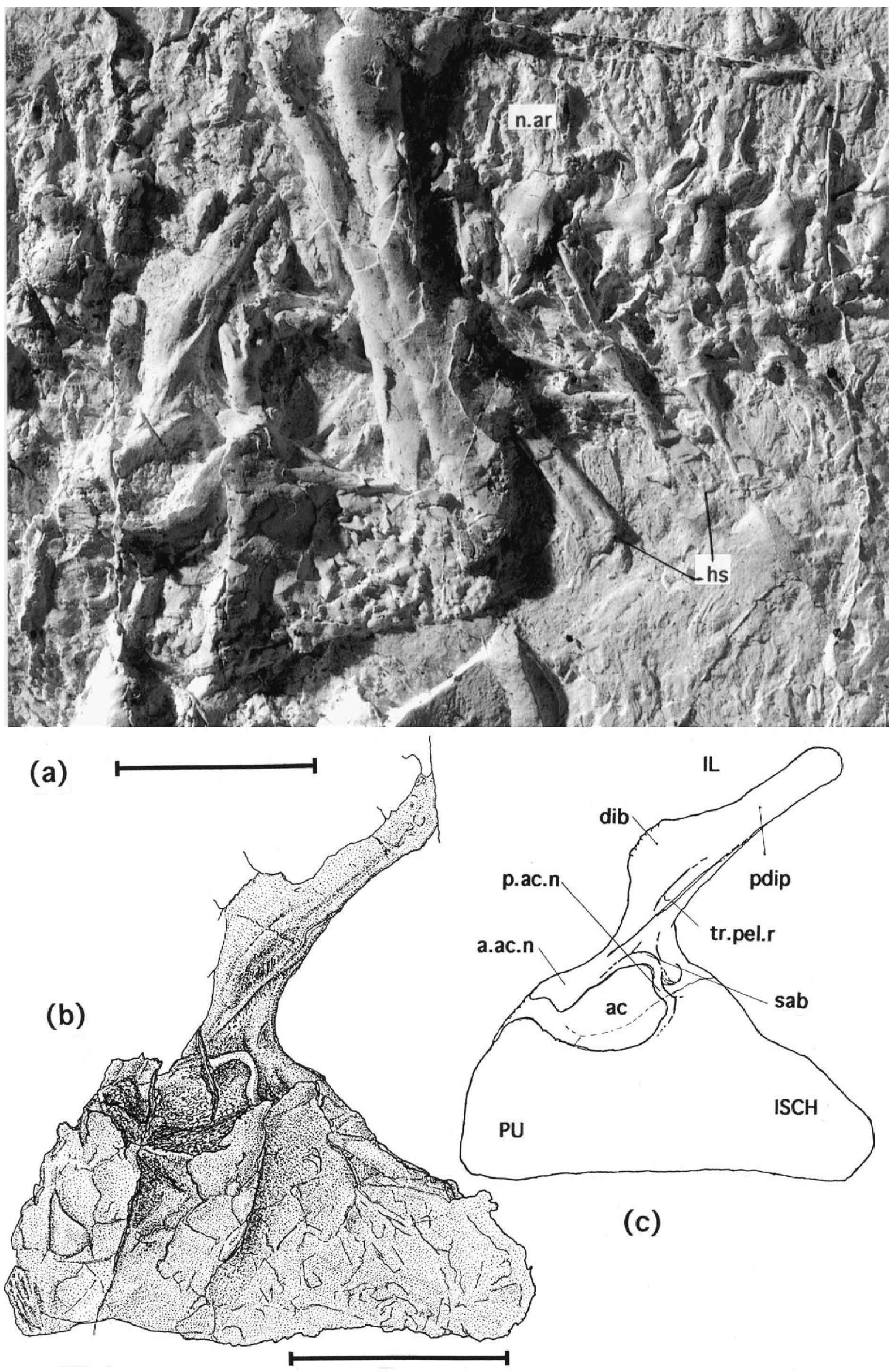

Figure 11 Caerorhachis bairdi Holmes \& Carroll: (a) MCZ 2271, left femur, left half of pelvic girdle and proximal caudal vertebrae; (b) camera lucida drawing of left half of pelvic girdle; (c) labelled reconstruction of left half of pelvic girdle; scale bars $=1 \mathrm{~cm}$. 


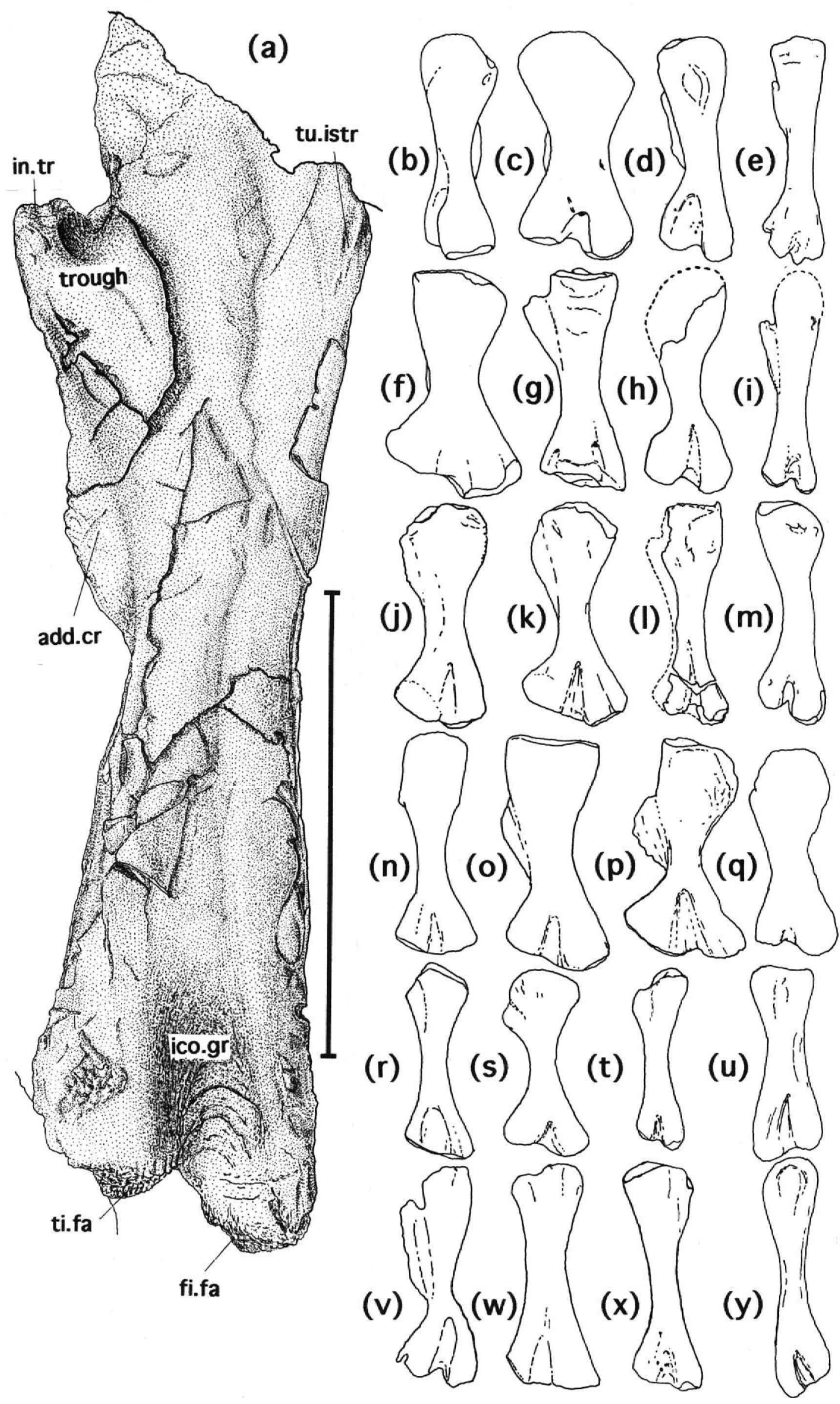


Watcheeria (Lombard \& Bolt 1995), among others. It is lower, however, than the ratio found in Eucritta (Clack 1998b, 2001 and 'anthracosaurs' (e.g. Silvanerpeton, Eldeceeon, Gephyrostegus, Proterogyrinus and Archeria; Romer 1957; Carroll 1970; Holmes 1984, 1989; Clack 1994; Smithson 1994). The proximal end of the tibia is comparable in size to the condylar region of the femur. The more deeply concave of the two margins of the shaft is likely to represent the mesial margin, based on a comparison with other early tetrapods, and indicates the presence of a distinct interepipodial space. The orientation of the tibiale and intermedium facets on the distal end of the bone suggests that the tibia is exposed in flexor view. A ridge is visible in the middle of the proximal half of the flexor surface (see also Romer 1957; Holmes 1984, 1989; Godfrey 1989). In general proportions and relative thickness, the ridge is similar to a similarly positioned structure in Eoherpeton (Smithson 1985b), and resembles a less robust and less oblique version of the rugose ridge for flexor muscle attachment described by Romer (1957) in Archeria, and by Holmes (1984) in Proterogyrinus. However, Caerorhachis shows only a faint indication of the rugosities noted by Romer (1957) and Holmes (1984). These appear as poorly preserved striations in several areas of the proximal half of the flexor surface. There is no posterior tibial flange, in contrast with Crassigyrinus (Panchen \& Smithson 1990), Tulerpeton (Lebedev \& Coates 1995) and Westlothiana (Smithson et al. 1994).

Little can be added to the description of the fibula and foot (Figs 13C, 14). A tarsal element, lying close to the epipodia, resembles a combined tibiale + centrale $_{4}$ as described by Holmes (1984) in Proterogyrinus. The '8-shaped' aspect of this element, with a distinct trough-like 'waist' between a smaller subpolygonal part and a larger subelliptical part, is tentatively interpreted as representing an earlier stage of the fusion between tibiale and centrale ${ }_{4}$ than that of Proterogyrinus. The intermedium carries a notch which gives it a vaguely Lshaped aspect. An L-shaped intermedium is regarded as a 'reptiliomorph' character by Lebedev \& Coates (1995) and Coates (1996).

3.7.3. Body armour. Several isolated gastralia are in ventral (external) aspect (Fig. 15). Their orientation is based on comparisons with gastralia of 'anthracosaurs' (Panchen 1985; Clack 1987b). A thick ridge, decreasing smoothly in height anteromesially and posterolaterally, lies close to one of two long margins of each gastralium. In several gastralia that occupy the ventral midline and the flanks of the animal, one extremity tapers gently and is approximately triangular, whereas the other is abruptly truncated and broadly spoonshaped. Similar differences have been recorded in the gastralia of other tetrapods, e.g. Crassigyrinus (Panchen 1985). Some gastralia appear subrectangular. Posterior to the ridge, the ventral surface of the gastralium is shallowly depressed, and was presumably overlapped by the adjacent posterior gastralium. Poorly preserved gastralia in dorsal aspect show an asymmetrical arrangement of concentric growth striations. Faint striations are sometimes visible on the spoon-shaped extremity of gastralia exposed in ventral view.

\section{Reconstruction and life-style}

The relative size and proportions of the hind-limb, a fully ossified tarsus, the lack of lateral line canals and lithological evidence point to Caerorhachis as a terrestrial vertebrate, although the depth of its tail suggests partially aquatic life habits (Holmes \& Carroll 1977; Smithson 1980; Carroll 1996). A semiterrestrial life-style is also indicated by the femur/puboischium length ratio (about 109.13\%), which is among the highest recorded ratios for Palaeozoic tetrapods. Such ratio compares well with those of such taxa as the 'anthracosaur' Gephyrostegus (106.52\%; Carroll 1970), the microsaurs Microbrachis and Tuditanus $(105.56 \%$ and $122.95 \%$, respectively; Carroll \& Gaskill 1978), the temnospondyl Dendrerpeton (105.71\%; Holmes et al. 1998), and various dissorophoid temnospondyls, among others. The extensive covering of small denticles on the palate and lower jaw of Caerorhachis, and the small size of dentary and maxillary teeth, are consistent with swift and/or slimy prey as possible food sources (e.g. invertebrates and/or small vertebrates). MCZ 2271 probably reached a subadult or young adult stage when it died, based on well-developed dermal sculpturing, tightly closed skull sutures, and ossified tarsus (Milner \& Sequeira (1994) and Berman et al. (2000) discuss similar features in other tetrapods).

Comparisons with broad-snouted, flat-headed, and shortribbed tetrapods (e.g. Balanerpeton and Eucritta) suggest that, like these, Caerorhachis probably used buccal pumping for air intake (Milner \& Sequeira 1994; Clack 2001). Although the skull depth cannot be reconstructed accurately, short trunk ribs and broad palate are consistent with this functional interpretation. Long and curved ribs, such as those of 'anthracosaurs', seymouriamorphs, diadectomorphs and crown-group amniotes (Romer 1956; Carroll 1970; Holmes 1984, 1989; Smithson 1985b, 1994; Clack 1994; Smithson et al. 1994; Berman et al. 2000; Klembara \& Bartik 2000), suggest that these taxa adopted costal ventilation for breathing. Also, they possess much deeper rib cages than Caerorhachis, as well as more elongate and deeper skulls. Size and curvature of the trunk ribs in Caerorhachis probably made them unsuitable for exclusively costal breathing. The curved ribs of many stereospondyls are likely to be a size-related feature (Milner 1988, 1990) in taxa that are otherwise adapted for buccal pumping.

Head/trunk proportions in Caerorhachis compare well with those of Ichthyostega(Jarvik 1980, 1996; Carroll 1988), Eucritta

Figure 12 Caerorhachis bairdi Holmes \& Carroll: (a) camera lucida drawing of left femur, extensor view; (b-y) reconstructions of left femora of early tetrapods, extensor view and to the same length: (b) Acanthostega gunnari; (c) Ichthyostega stensioi; (d) Tulerpeton curtum; (e) Greererpeton burkemorani; (f) Whatcheeria deltae; (g) Crassigyrinus scoticus; (h) Eoherpeton watsoni; (i) Caerorhachis bairdi; (j) Archeria crassidisca; (k) Proterogyrinus scheelei; (1) Westlothiana lizziae; (m) Dimetrodon limbatus; (n) Discosauriscus austriacus; (o) Seymouria baylorensis; (p) Limnoscelis dynatis; (q) Eldeceeon rolfei; (r) Rhynchonkos stovalli; (s) Trachystegos megalodon; (t) Tuditanus punctulatus; (u) Sauropleura scalaris; (v) Balanerpeton woodi; (w) Mastodonsaurus giganteus; (x) Acheloma sp.; (y) Scincosaurus crassus. Redrawn and modified from the following sources: b, Coates 1996; c, Jarvik 1996; d, Lebedev \& Coates 1995; e, Godfrey 1989; f, Lombard \& Bolt 1995; g, Panchen \& Smithson 1990; h, Smithson 1985b; i, this paper; j, Romer 1957; k, Holmes 1984; 1, Smithson et al. 1994; m, o, Romer 1956; n, Klembara \& Bartik 2000; p, Berman \& Sumida 1990; q, Smithson 1994; r-t, Carroll \& Gaskill 1978; u, y, Bossy \& Milner 1998; v, Milner \& Sequeira 1994; w, Schoch \& Milner 2000; x, Sullivan et al. 2000. Scale bar $=1 \mathrm{~cm}$. 


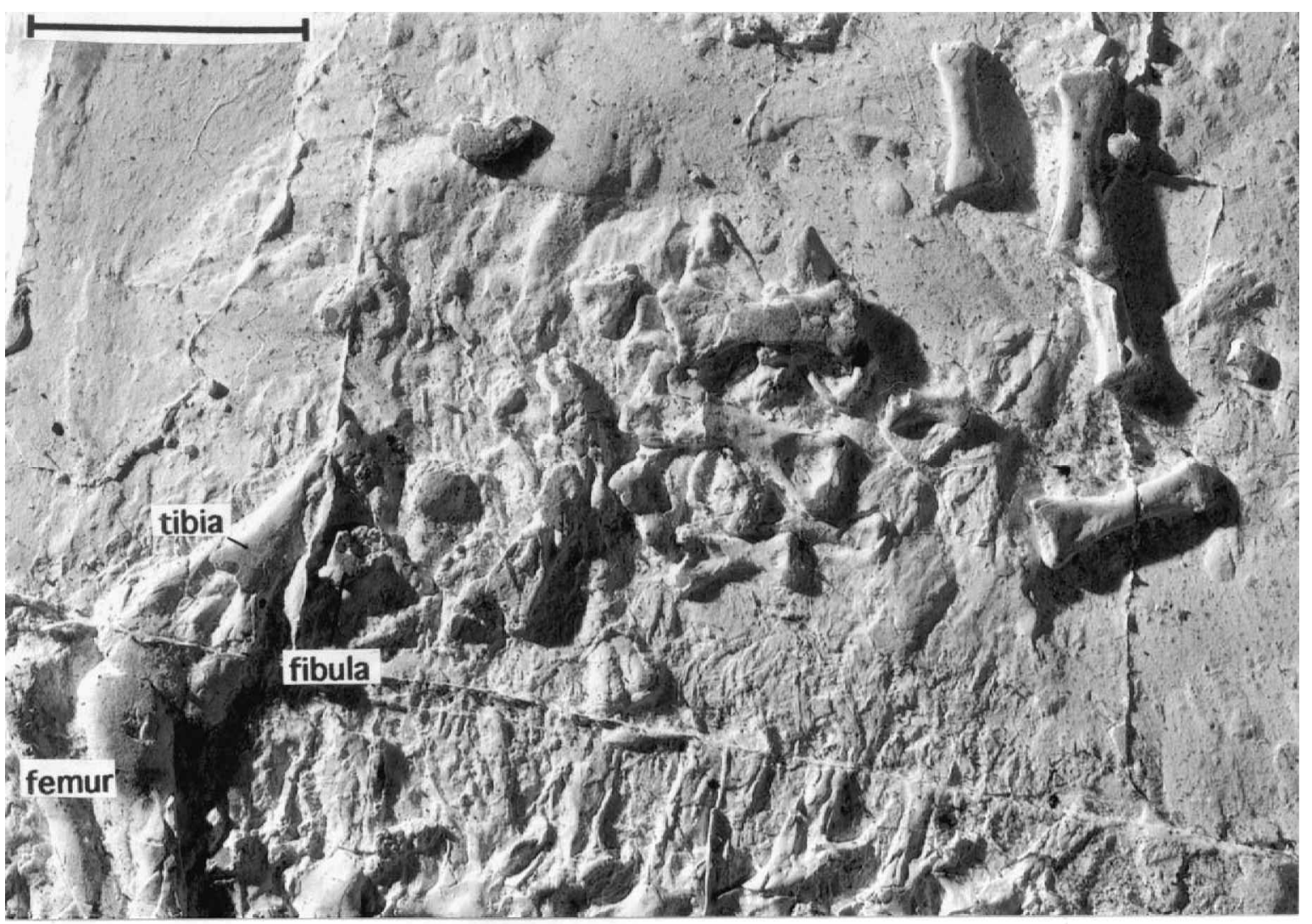

(a)
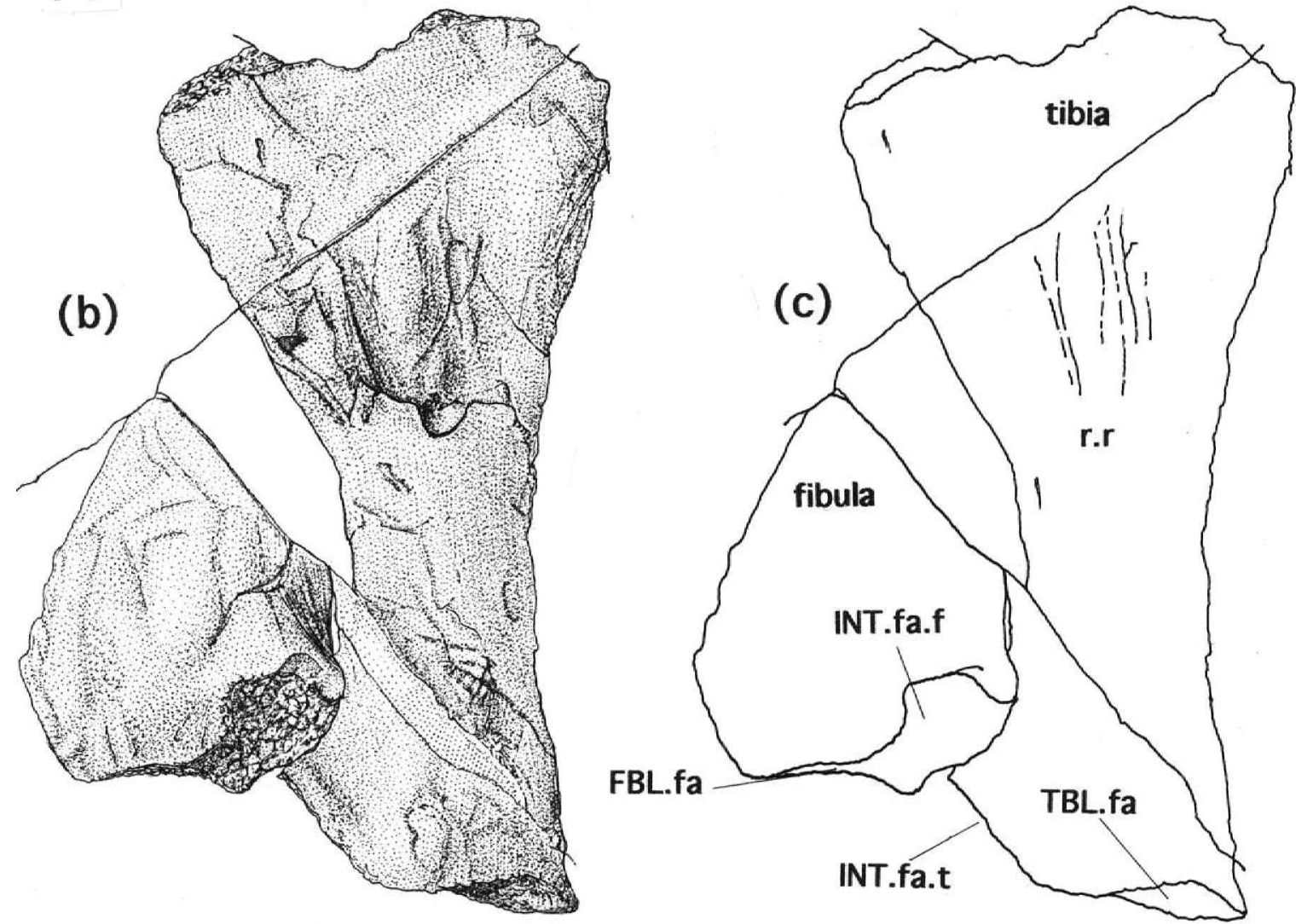

Figure 13 Caerorhachis bairdi Holmes \& Carroll: (a) MCZ 2271, left tibia, fibula, and foot; (b) camera lucida drawing of left tibia and fibula in flexor view; (c) labelled diagram of left tibia and fibula; scale bars $=1 \mathrm{~cm}$. 


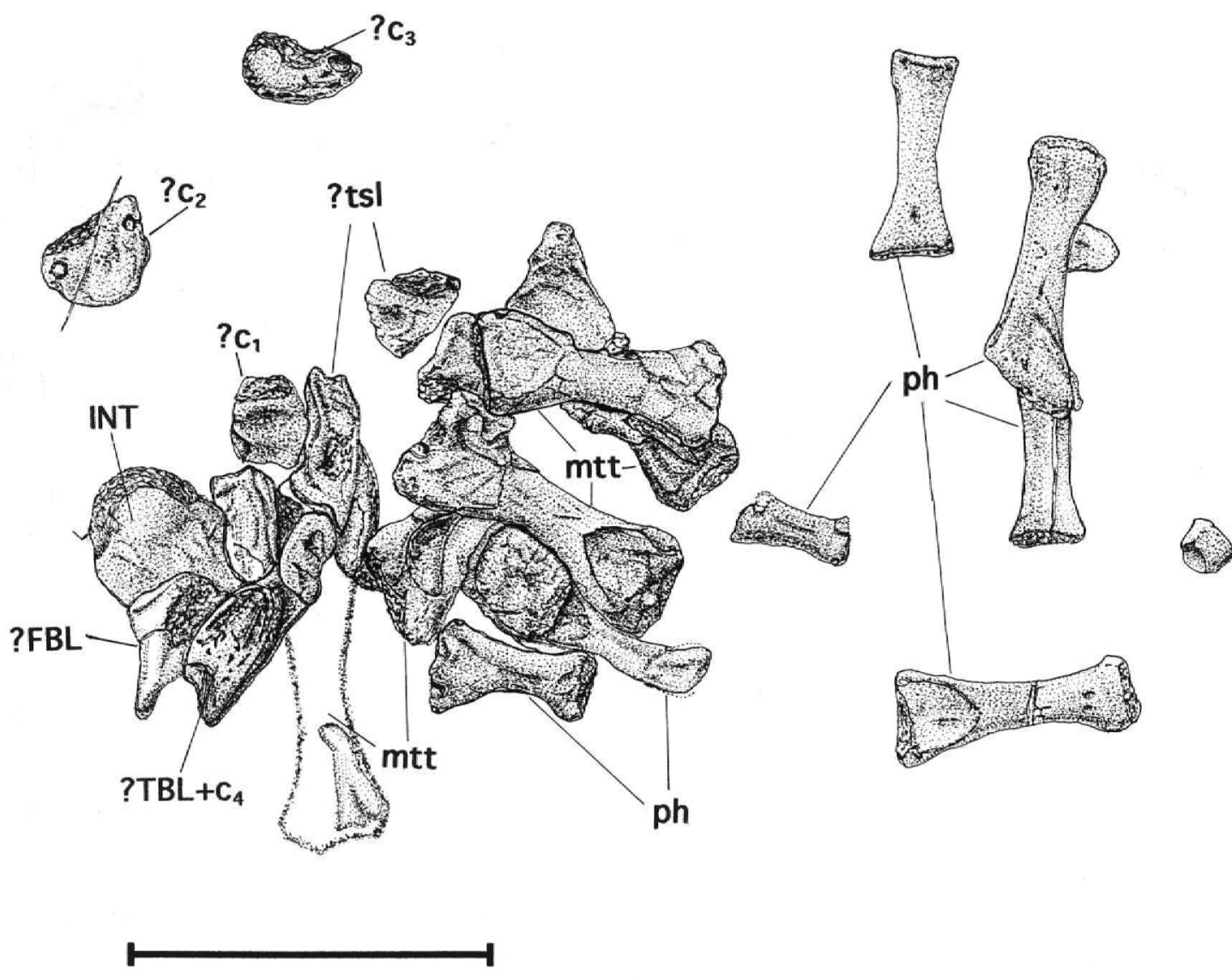

Figure 14 Caerorhachis bairdi Holmes \& Carroll: camera lucida drawing of left foot; scale bar $=1 \mathrm{~cm}$.

(Clack 1998b, 2001) several temnospondyls (e.g. Cacops, Eryops, Dendrerpeton, many stereospondyls, etc.; Williston 1910; Romer 1947, 1966; Moulton 1974; Holmes et al. 1998), some 'anthracosaurs' (e.g. Gephyrostegus, Carroll 1970), the microsaur Pantylus (Carroll \& Gaskill 1978), certain diplocaulid nectrideans (A. C. Milner 1980; Bossy \& Milner 1998), etc. Interestingly, the presacral vertebral count of these taxa ranges between 22 and 24, except in Caerorhachis (32), and in diplocaulids (fewer than 18).

\section{Affinities}

\subsection{Holmes \& Carroll's interpretation}

Before discussing the inclusion of Caerorhachis in various cladistic analyses, we summarise previous researchers' views on the affinities of this tetrapod.

5.1.1. Is Caerorhachis an edopoid? Holmes \& Carroll (1977) assigned Caerorhachis, with some uncertainty, to the family Dendrerpetontidae, superfamily Edopoidea. However, A. R. Milner (1980) viewed characters used by them to ally dendrerpetontids to edopoids as plesiomorphic for temnospondyls or even for tetrapods. His emended Edopoidea excluded Dendrerpeton, regarded as one of the most primitive and generalised temnospondyls (Romer 1947; Berman et al. 1985; Godfrey et al. 1987; Milner \& Sequeira 1994; Yates \& Warren 2000; but see Holmes et al. 1998). Edopoids are medium- to large-sized, early-mid Pennsylvanian to earliest Permian temnospondyls resembling alligators or gharials in skull morphology (Milner 1990; Milner \& Sequeira 1998). Recent reviews (Sequeira \& Milner 1993; Milner \& Sequeira 1994, 1998; Sequeira 1996) clarify their limits and content, identifying three cranial synapomorphies for the group: (1) premaxilla with marginal anteroposterior elongation and broad dorsomedial surfaces; (2) jugal/prefrontal suture excluding lacrimal from orbit margin; (3) substantial jugal contribution to preorbital region through development of broad jugal/ lacrimal suture. Unfortunately, Caerorhachis cannot be assessed for any of these characters.

Despite his reservations about the temnospondyl nature of Caerorhachis, A. R. Milner (1980) did not rule out the possibility that it might represent the juvenile of either a large, long-snouted, and Edops-like form, or a more primitive 'pre-edopoid' temnospondyl. This interpretation was based on such morphological similarities between Caerorhachis and Edops as 'canine peaks', mediodorsal orientation of articular, and shape of pterygoids and palatal vacuities. However, 'canine peaks' are observed in other tetrapods (e.g. Crassigyrinus, Megalocephalus, Pholiderpeton, Proterogyrinus, etc.; Panchen 1973, 1985; Beaumont 1977; Holmes 1984; Clack 1987b, 1998a). In addition, both jaw rami of Caerorhachis have undergone disruption and flattening, causing the articular to face almost entirely mesially.

The similar morphology of pterygoids and palatal vacuities in Caerorhachis and Edops deserves some comment. Knowledge of the Edops palate rests mostly on a single large skull (Romer \& Witter 1942). Its spindle-like palatal vacuities resemble narrower, and more elongate versions of those of Caerorhachis. In Edops, and perhaps also in Caerorhachis, the pterygoids meet anteriorly along a median suture (see 'Description' above). This feature may be related to the large size and broad preorbital region of Edops (A. R. Milner 1980). It may have reinforced the anterior third of the palate, counteracting biting forces generated when the animal fed upon large prey, 

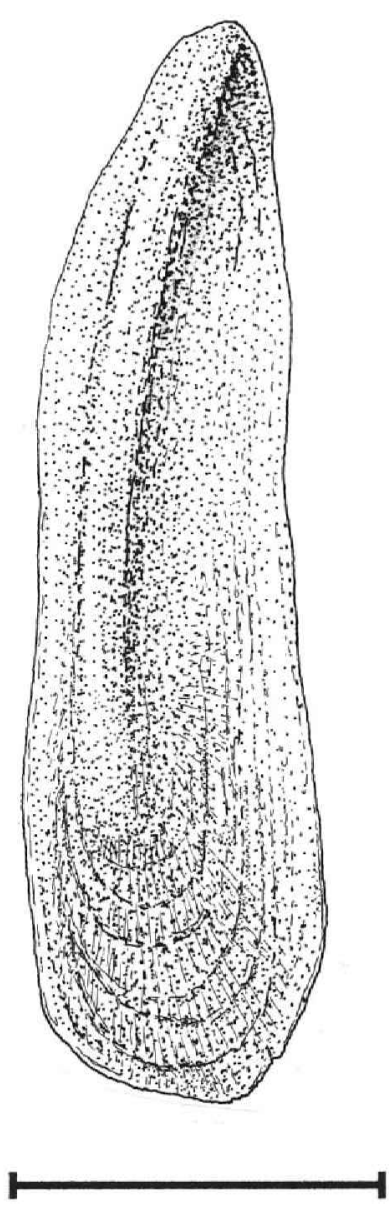

Figure 15 Caerorhachis bairdi Holmes \& Carroll: reconstructed gastralium in ventral aspect; scale bar $=1 \mathrm{~mm}$.

as suggested by analysis of stress distribution in the skull of modern crocodiles (Busbey 1995). Such a strengthening function, however, is difficult to reconcile with the much smaller size of the Caerorhachis skull.

Holmes et al. (1998) noted that, in those temnospondyls in which growth series are known, the palatal vacuities undergo [almost] isometric changes. If this is true for Caerorhachis and Edops, then A. R. Milner's (1980) hypothesis that the former may represent a juvenile, edopoid(-like) temnospondyl cannot be dismissed altogether. Obviously, lack of additional fossil material makes it impossible to test such a hypothesis. However, elongate and spindle-shaped palatal vacuities are present in several other Palaeozoic taxa, such as colosteids (Smithson 1982; Hook 1983), various nectrideans (Bossy \& Milner 1998), many microsaurs (Carroll \& Gaskill 1978), some 'anthracosaurs' (e.g. Carroll 1970; Holmes 1984, 1989), etc. The validity of this character is, therefore, questionable. Furthermore, the insertion of the anterior ends of the palatal rami of the pterygoids between the vomers is also documented in certain microsaurs and nectrideans, among others. The recently described, primitive edopoid Adamanterpetonohioensis (Milner \& Sequeira 1998) may represent, in some respects, a better model for inferring the juvenile condition of Edops than Caerorhachis does. Although the palatal configuration of Adamanterpeton is superficially similar to that of Caerorhachis (e.g. presence of relatively small, albeit round, interpterygoid vacuities; exclusion of vomers and palatines from such vacuities), it differs from the latter in the greatly expanded vomers, shape and relative size of the choanae, morphology and extension of the quadrate and palatine rami of the pterygoids, and configuration of the parasphenoid.

5.1.2. Is Caerothachis a temnospondyl? Apart from palatal vacuities, hardly any character of Caerorhachis suggests resemblance to Edops or other temnospondyls. According to A. R. Milner (1980, 1990), if Caerorhachis is placed within temnospondyls, then several cranial and postcranial features of this tetrapod appear to be autapomorphic. As such, they cannot establish its relationships to other temnospondyls. Furthermore, some of the characters employed by Holmes \& Carroll (1977) to support the temnospondylaffinities of Caerorhachis are either primitive for tetrapods (e.g. dermal sculpture; supratemporal/postparietal suture; Milner \& Sequeira 1994; Coates 1996), or of uncertain polarity (e.g. solid fusion between cheek and skull table; uniramous ilium; Milner 1993b; but see Coates 1996). Smithson (1982) placed emphasis on the occurrence of enlarged pleurocentra to question Holmes \& Carroll's (1977) interpretation. Holmes (1984) acknowledged that the vertebrae of various 'anthracosaurs' show little resemblance to the cylindrical centra of amniotes s.s., microsaurs or the temnospondyl Doleserpeton. He suggested that the morphological condition of Caerorhachis, although similar to that of certain 'anthracosaurs', probably represents an early stage in the development of gastrocentrousvertebrae in temnospondyls. Doleserpeton would display the culmination of such a development. The distribution of gastrocentrous vertebrae in Palaeozoic tetrapods would imply that enlarged pleurocentra developed convergently in temnospondyls and 'anthracosaurs', although ' . . . [the] specific relation [of Caerorhachis], if any, to Doleserpeton is unclear' (Holmes 1984, p. 507). However, Doleserpeton is usually regarded as one of the most derived temnospondyls, and is placed by some authors as the immediate sister taxon of crown-group lissamphibians (Bolt 1969, 1991; Milner 1988, 1990). Therefore, its close relationship with Caerorhachis is implausible.

Recently, Yates \& Warren (2000) presented a cladistic analysis of 'higher' temnospondyls (i.e. exclusive of edopoids, Dendrerpeton and Balanerpeton). Of the two apomorphies used by them to assess their ingroup monophyly ( fide Laurin \& Reisz 1997, and Laurin 1998a; but see Bolt 1979, 1991, and Milner 1988, 1990, 1993b), the first (loss of entepicondylar foramen) cannot be evaluated in Caerorhachis, whereas the second (posterior coronoid visible in lateral view) is absent. However, there remains a possibility that Caerorhachis falls outside Yates \& Warren's (2000) ingroup, and represents a more primitive temnospondyl. Milner (1988) used six characters to define the basal temnospondyl node, including taxa not considered by Yates \& Warren (2000): (1) manus with four digits; (2) semicircular tympanic notch not reaching quadrate, and dorsolaterally oriented stapes; (3) round interpterygoid vacuities at least half as wide as skull and bordered by triradiate pterygoids; (4) broad, flat vomers widely separating choanae; (5) straight and short ribs; (6) parasphenoid with parallel-sided, elongate cultriform process overlapping or suturing with vomers and with broad, flat basal plate. Two of Milner's (1988) characters $(1,2)$ cannot be observed in Caerorhachis; three (3-5) are not matched by its morphology; and one (6) can be evaluated only partially, although it does not seem to suggest any resemblance to temnospondyls (see 'Description' above). An additional feature employed by Milner (1990, 1993b) to characterise temnospondyls, not considered further by Milner \& Sequeira (1994), is the occurrence of a posterolateral flange on the palatine ramus of the pterygoid, not present in Caerorhachis. A rudimentary flange on the palatine ramus is also observed in some microsaurs and nectrideans (Carroll \& Gaskill 1978; Bossy \& Milner 1998), but it is rarely as well developed as those of various temnospondyls. The flange 
confers a characteristic anteromesial constriction to the subtemporal fossa (Romer 1947), and was lost twice during the evolutionary history of temnospondyls, according to Yates \& Warren (2000; but see Milner 1990). Other characters discussed by Milner (1990) and Milner \& Sequeira (1994) in the context of basal temnospondyls relate to premaxillary shape (not observed in Caerorhachis) and presacral vertebral count. The vertebral count of Caerorhachis exceeds 25, considered by Milner (1990) to be primitive for temnospondyls.

Caerorhachis differs from temnospondyls also in details of the lower jaw (Fig. 8). Thus, in several early and many later temnospondyls, the shallow, anterior two-thirds of the lower jaw ramus is delimited more or less sharply from its posterior third by a sudden decrease in jaw depth (Milner \& Sequeira 1994, 1998; Holmes et al. 1998), regardless of the absolute size of the lower jaw. The ventral margin of the anterior twothirds may be straight, gently concave or even sinuous in lateral aspect, and merges with a broadly convex, or sharply bent posteroventral angle. The upper dentary margin is often straight when viewed laterally, except for a short, sloping portion anterior to the surangular/coronoid crest (Ahlberg \& Clack 1998). The dorsolateral margin of the adductor fossa is subhorizontal and often parallel to the dentary margin. By contrast, the lower jaw of Caerorhachis is similar in general proportions to those of the 'anthracosaurs' Archeria and Pholiderpeton (Clack 1987b; Holmes 1989), or the baphetid Megalophalus (Beaumont 1977). Its profile is smooth along its ventral and posterior margins, whereas the dentary margin is gently concave. Additional differences between Caerorhachis and temnospondyls are observed at the level of the Meckelian foramina and of the mesial laminae of the infradentaries. Thus, except for some taxa (e.g. Milner \& Sequeira 1994), several temnospondyls show a small, subelliptical or circular posterior Meckelian foramen between prearticular, angular and postsplenial, or between prearticular and angular. Often, a small, anterior Meckelian foramen is visible between prearticular, splenial and postsplenial, or between splenial and postsplenial. Caerorhachis resembles Eoherpeton in showing a row of three foramina between the mesial laminae of the infradentaries and the prearticular. Such foramina are intermediate in relative size between those of Eoherpeton and those of Archeria, Pholiderpeton and Proterogyrinus (Fig. 8). As in these taxa, the rearmost extension of the mesial lamina of the splenial in Caerorhachis appears to be closer to the anterior margin of the adductor fossa than to the symphysial region of the mandible. This condition is found also in other taxa (see 'Concluding remarks').

\subsection{Other interpretations}

Milner \& Sequeira (1994) noted similarities between Caerorhachis and Baphetes in the configuration of the anterior part of the palate, in the shape and position of the choanae, and in the proportions of the palatines and vomers. They hypothesised that Caerorhachis represents a grade of anatomical organisation below temnospondyls comparable to that of baphetids.

More recently, Coates (1996) suggested that Caerorhachis may be more closely related to amniotes than to lissamphibians, based on the shape of the centra, the morphological distinction between cervical and trunk ribs, the greatly reduced dorsal process of the ilium, a transverse pelvic ridge sweeping towards the ventral edge of the posterior iliac process, and an L-shaped tarsal intermedium. Based on inferred character optimisation on his preferred cladogram, Coates (1996) suggested that Caerorhachis is more crownward than Westlothiana on the amniote stem-group, and basal with respect to 'anthracosaurs'.

\subsection{Coates' 1996 matrix}

Coates' (1996) study (18 taxa; 76 characters; 36 characters unscorable for Caerorhachis) elaborates upon Lebedev \& Coates's (1995) work, and traces the lissamphibian/amniote split back to Palaeozoic taxa. PAUP* finds six trees at 144 steps (C.I. $=0.5839$; R.I. $=0.7077$; R.C. $=0 \cdot 4276$ ) that place Caerorhachis as sister group of Westlothiana. Optimisation of scorable character changes for (Caerorhachis + Westlothiana) is as follows: 6 (absence of tooth row on parasymphysial plate), 7 (absence of parasymphysial foramina), 58 (absence of tabular horn with superficial and deep components). Reweighting characters yields three trees, but does not affect the relationships of Caerorhachis. The (Westlothiana + Caerorhachis) clade has a low bootstrap support $(60 \%)$ and decay index (1). The (Archeria + (Proterogyrinus + Westlothiana) $)$ branching sequence is the reverse of that found in the original analysis.

Inspection of the published version of Coates' matrix reveals minor inaccuracies related to four characters. The states of characters 65 and 74, describing the occurrence of a pentadactyl and a tetradactyl manus, respectively, are clearly complementary for all of Coates' post-Devonian tetrapods in which the manus is known. In the original matrix, Westlothiana is coded as 1 for character 65 , and as unknown for character 74. Obviously, the cell entry for character 74 should be 0 , since Westlothiana is assumed to have possessed a pentadactyl manus (though its digit count is not certain; Smithson, pers. comm.). There is partial redundancy associated with characters 21 and 35 . Character 21 refers to the absence or presence of coronoid fangs. Character 35 refers to the occurrence (or lack thereof) of the condition 'coronoid fangs lost'. In the original matrix, the codings related to these two characters are complementary for most taxa. However, Whatcheeria is coded as 0 for character 21 , and as unknown for character 35 . After character 35 is removed, the amended version of Coates' matrix yields 20 trees (Fig. 16A; strict consensus). The characters supporting the position of Caerorhachis are unchanged.

\subsection{Paton, Smithson \& Clack's 1999 matrix}

Paton et al. (1999) analysed a modified and enlarged version of Clack's (1998a,b) data sets (78 cranial, 33 postcranial characters; 55 characters unscorable for Caerorhachis) in order to place systematically Casineria. PAUP* finds 18 trees at 345 steps (Fig. 16B; strict consensus). Caerorhachis is paired with 'anthracosaurs' in all minimal trees, albeit with low decay index (1) and bootstrap support (17\%). As an example of character optimisation, in those trees in which Whatcheeria, Eucritta and Baphetes are intermediate in position between 'anthracosaurs' and Seymouria, the position of Caerorhachis is supported by the following scorable characters: 8 (lateral edge of intertemporal not interdigitating with cheek), 25 (postorbital suture to skull table (intertemporal) smooth), 77 (skull table longer than broad), 98 (presence of V-shaped grooves on ends of phalanges), and 104 (one or two pairs of postsacral ribs approaching length of trunk ribs). Character reweighting yields a single tree (Fig. 16C), but does not affect the position of Caerorhachis. Removing Eucritta gives two trees at 334 steps (Fig. 16D) in which Casineria is forced out of the amniotes s.s., and placed with 'anthracosaurs' in two different positions. Characters supporting the position of Caerorhachis are the same in both trees, and most of them match the apomorphy list found in the original parsimony run.

\subsection{Ahlberg \& Clack's 1998 matrix}

Ahlberg \& Clack's (1998) analysis of lower jaw characters tried to assess the relative positions of early taxa known only from their mandibles, and discussed key characters that may allow 


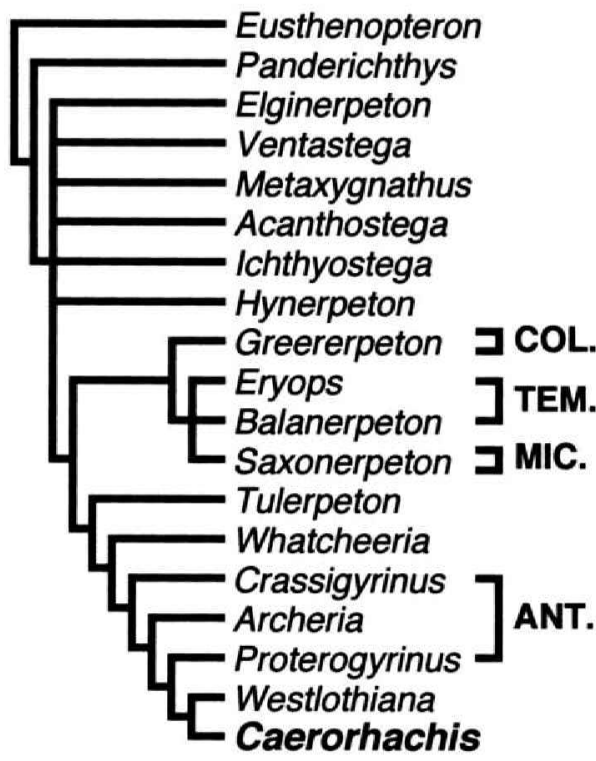

Coates' (1996) analysis:

strict consensus of 20 trees at 142 steps:

C.I. $=0.5852 ;$ R.I. $=0.7053 ;$ R.C.$=0.4271$

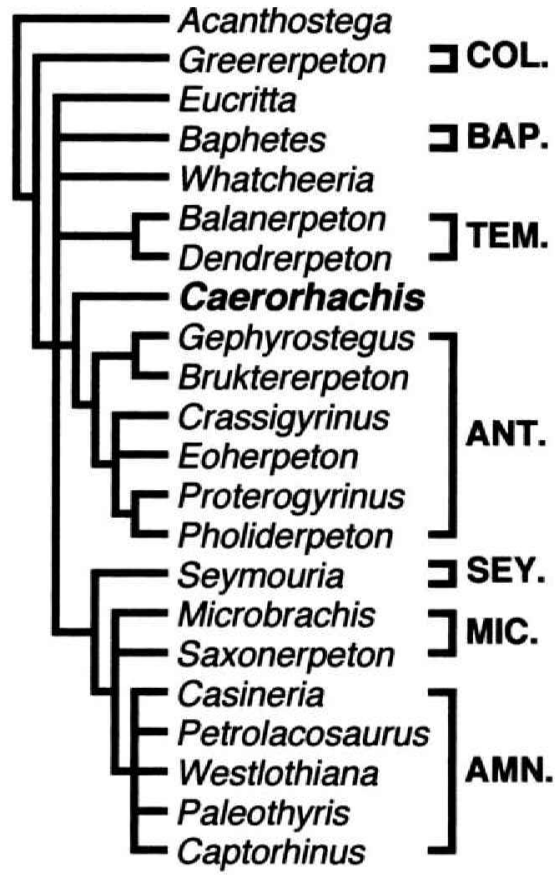

Paton et al.'s (1999) analysis: strict consensus of 18 trees at 345 steps; C.I. $=0.4395 ;$ R.I. $=0.5455 ;$ R.C.$=0.2451$

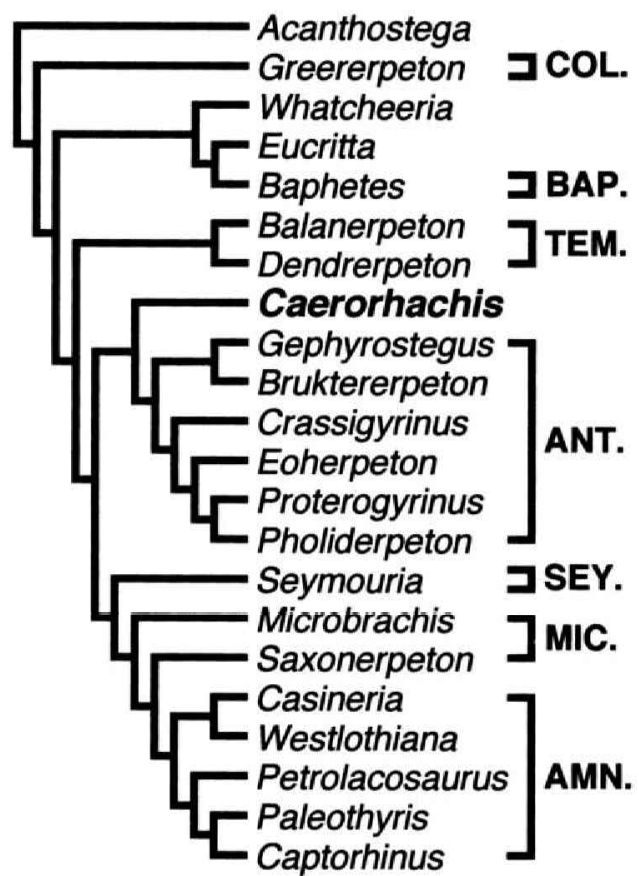

Paton et al.'s (1999) analysis: single tree after reweighted run; C.I. $=0.6163 ;$ R.I $=0.7821 ;$ R.C. $=0.5037$

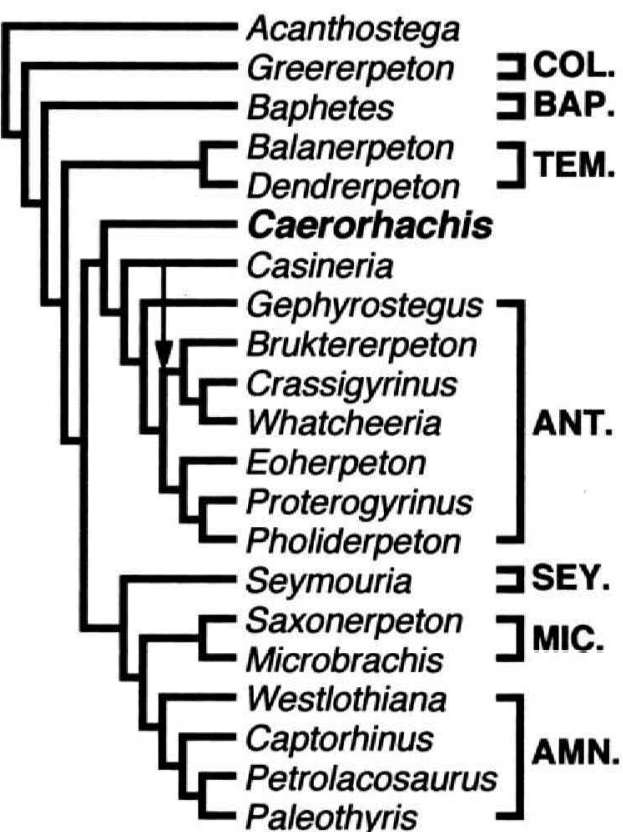

Paton et al.'s (1999) analysis:

strict consensus of 2 trees at 334 steps; arrow indicates the 2 positions of Casineria after exclusion of Eucritta; C. $I=0.4526 ;$ R. $I=0.5514 ; R . C .=0.2559$

Figure 16 Cladistic analyses including Caerorhachis: (a) Coates 1996; (b-d) Paton, Smithson \& Clack 1999. Abbreviations as follows: AMN. = amniotes; ANT. = anthracosaurs; BAP. = baphetids; COL. = colosteids; DIA. $=$ diadectomorphs; LIS. = lissamphibians; MIC. $=$ microsaurs; NEC. $=$ nectrideans; SEY.$=$ seymouriamorphs; TEM. = temnospondyls. 
identification of isolated or disrupted tetrapod jaw fragments. The relationships of various groups differ from those of previous studies (e.g. temnospondyls and 'anthracosaurs' appear to be polyphyletic). Ahlberg \& Clack's matrix consists of 26 taxa and 50 characters. We note that their character 48 (presence or absence of a postsplenial pit line) was coded as 1 (absence) in four taxa that lack a postsplenial altogether (their character 33), namely the nectrideans Sauropleura and Diploceraspis, and the amniotes Eocaptorhinus and Ophiacodon. These taxa should be coded as ?, in agreement with Ahlberg \& Clack's use of question marks to indicate inapplicable characters. We describe the results deriving from two out of several combinations of weighting and ordering regimes.

5.5.1. All characters unweighted and unordered. PAUP* yields 968 trees at 116 steps (C.I. $=0 \cdot 4779$; R.1. $=0 \cdot 7122$; R.C. $=$ $0 \cdot 35)$. The proximal part of the strict consensus fails to provide resolution for all Devonian taxa, in contrast with the results obtained by Ahlberg \& Clack, who retrieved partial structure in the bottom half of their consensus tree. Whatcheeria is also included in such basal polytomy. More distally, Greererpeton, Crassigyrinus, Megalocephalus and Caerorhachis are successively more closely related to a poorly resolved clade comprising Cochleosaurus, Phonerpeton, Eoherpeton; Gephrostegus; Microbrachis; Discosauriscus; (Pholiderpeton + Proterogyrinus); (Balanerpeton + Platyrhinops); and an unresolved amniotenectridean clade. The position of Caerorhachis receives a $29 \%$ bootstrap support. We selected arbitrarily one tree to examine optimisation of character changes supporting the position of Caerorhachis. The arrangement of taxa distal to the node subtending Caerorhachis features 'anthracosaurs' as a clade consisting of (Pholiderpeton + Proterogyrinus) paired with (Eoherpeton + Gephyrostegus). Phonerpeton and Cochleosaurus are successively more closely related to such a group. All these taxa join: (Balanerpeton + Platyrhinops); (Microbrachis + Discosauriscus); (Sauropleura + (Ophiacodon + (Eocaptorhinus + Diploceraspis)). The position of Caerorhachis is supported by the following scorable characters: 7 (presence of posterodorsal process of posterior coronoid), 44 (presence of surangular crest), 45 (absence of mandibular sensory canal).

5.5.2. Characters 36 and 46 ordered; all characters reweighted. With characters 36 and 46 ordered (referring, respectively, to the position of the centre of radiation on the prearticular, and to the degree of enclosure of the mandibular sensory canal), a reweighted run gives 90 trees (Fig. 17A; strict consensus). The number, statistics and state changes of the characters supporting the position of Caerorhachis in one of the minimal trees are almost identical to those of the unweighted and unordered analysis. The position of Caerorhachis receives a $35 \%$ bootstrap support. Work in progress on an expanded version of Ahlberg \& Clack's matrix (including such additional characters as proportions of infradentaries, extension of their mesial laminae, size and position of Meckelian foramina, etc.) retrieves traditional taxonomic groups, including 'anthracosaurs' and temnospondyls. These results, although preliminary, suggest that the phylogenetic signal present in the original matrix is in fact sensitive to character sampling. For example, Caerorhachis can be linked to 'anthracosaurs', and the nectridean-amniote polytomy can be resolved in favour of monophyletic nectrideans paired with monophyletic amniotes.

\subsection{Laurin's 1998a matrix}

Laurin's (1998a) database evolved from Carroll's (1995), with additional characters. It covered all major Palaeozoic groups, and was intended to solve the problem of lissamphibian origins. Unlike previous analyses, it included representatives of Recent lissamphibians, as well as primitive crown-group amniotes. In Laurin's phylogeny, lissamphibians are linked to a paraphyletic 'lepospondyls', whereas diadectomorphs are the only Palaeozoic clade placed in the stem-group amniotes. Laurin's matrix encompasses 155 characters (47 scorable for Caerorhachis) coded for 43 living and extinct taxa. Inclusion of Caerorhachis and Whatcheeria does not alter the tree configuration. We found two trees (Fig. 17B; strict consensus), in which Caerorhachis is nested between a temnospondyl clade and a monophyletic 'anthracosaur' clade. The position of Caerorhachis is supported by the following scorable characters: 3 (dermal sculpture of shallow and widely spaced pits surrounded by smooth bony surface), 6 (jaw articulation near to occiput level), 113 (capitulum of mid-presacral vertebrae articulates to intercentrum and pleurocentrum of same segment; see also comments below), 119 (absence of uncinate processes), 143 (iliac blade with discrete dorsal and posterior flanges), 151 (three phalanges in second pedal digit), 153 (five phalanges in fourth pedal digit). The position of Caerorhachis receives a $22 \%$ bootstrap support. However, the $50 \%$ majority-rule consensus tree shows Caerorhachis nested between (Proterogyrinus + Archeria) and Gephyrostegidae in a paraphyletic 'anthracosaurs'. These are placed between loxommatids and temnospondyls.

Of all the characters (scorable and unscorable) optimised at the internode leading to Caerorhachis and more crownward tetrapods, those with the highest consistency indexes, 98 and 113, are discussed here. Optimisation of character 98 assigns state 3 to the morphologicalcondition of centra in Caerorhachis (circular intercentra and pleurocentra). We decided to code Caerorhachis as unknown, because its vertebrae, although similar to those of 'anthracosaurs' in the possession of enlarged pleurocentra, differ from those of seymouriamorphs, Westlothiana, and amniotes s.s. Laurin's coding for character 98 encompasses a large but not exhaustive set of vertebral morphologies; however, we did not include an alternative state for Caerorhachis in order to retain as much of the original matrix structure as possible. Uncertainty characterises the coding for character 113, describing the modality of articulation of the mid presacral ribs to the vertebrae. We originally coded Caerorhachis as 1, based on comparisons with Archeria, Proterogyrinus, certain seymouriamorphs and Westlothiana, in which the capitulum of the mid-presacral vertebrae articulates to the intercentrum and pleurocentrum of the same vertebral segment. However, recoding Caerorhachis as unknown for character 113 does not affect the analysis.

\section{Concluding remarks}

Various features of the lower jaw, palate, axial and appendicular skeleton are consistent with the revised interpretation of Caerorhachis as a basal 'anthracosaur'. Some of the characters listed in the 'Diagnosis' under various headings are also observed (although not always in conjunction) in 'anthracosaurs', seymouriamorphs, diadectomorphs and several primitive crown-group amniotes. Therefore, it is justifiable to regard them as possible generalised amniote apomorphies at different levels of inclusiveness (see discussion below). Analysis of character distribution supporting the placement of Caerorhachis adds to the long-standing view that 'anthracosaurs' may represent an early reptiliomorph radiation, despite their very primitive nature (e.g. Panchen \& Smithson 1988; Smithson et al. 1994; Clack 1998b, 2001; Paton et al. 1999). Furthermore, detailed recent investigations into the postcranium, braincase and occiput morphology of seymouriamorphs and diadectomorphs lend support to the amniote-like affinities of these clades (e.g. Sumida et al. 1992; Sumida 1997; Berman 2000; Berman et al. 2000). However, a more precise assessment of 


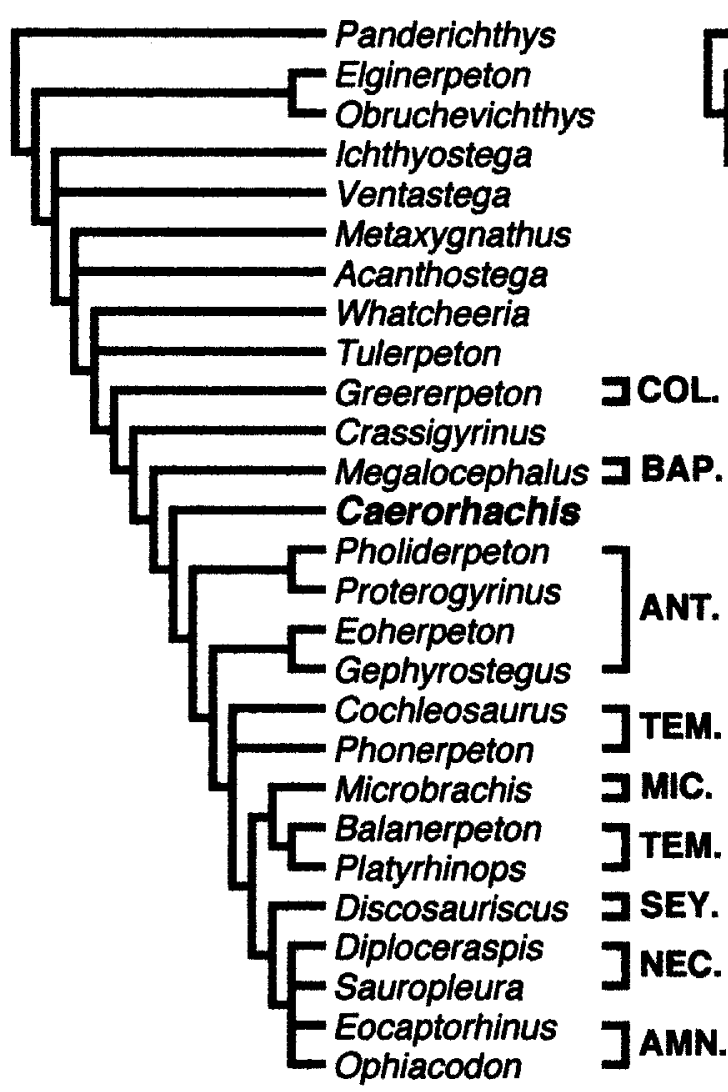

Ahlberg \& Clack's (1998) analysis: all characters reweighted; characters 36 and 46 ordered; strict consensus of 90 trees; C. $I .=0.6487 ;$ R. $I .=0.8559 ;$ R.C. $=0.5749$

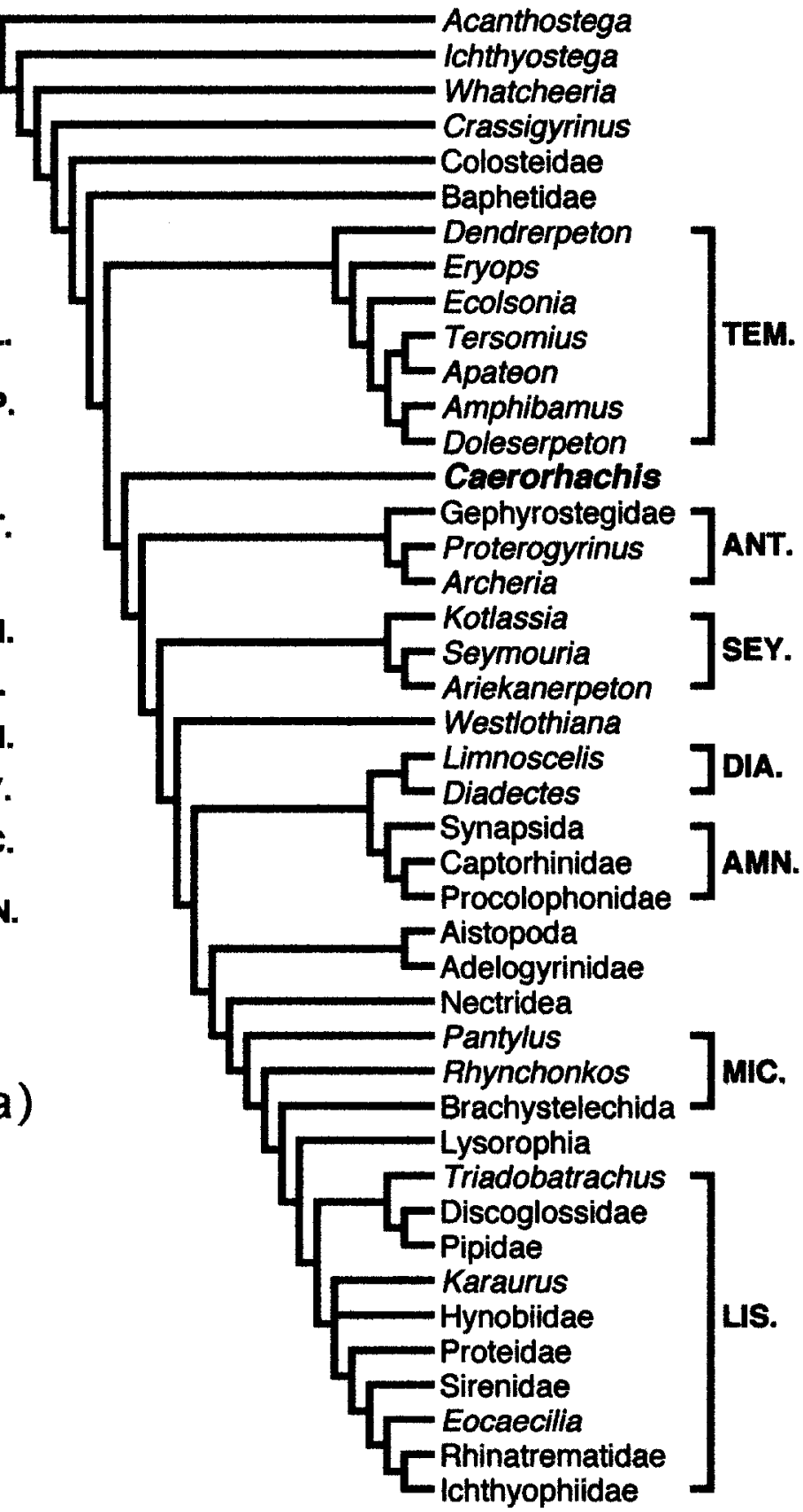

Laurin's (1998a) analysis: strict consensus of 2 trees at 675 steps; C.I. $=0.4621 ;$ R.I $=0.7202 ;$ R.C. $=0.334$

Figure 17 Cladistic analyses including Caerorhachis: (a) Ahlberg \& Clack 1998; (b) Laurin 1998a; abbreviations as in Figure 16.

the order of character acquisition in the amniote stem-group must await a large-scale analysis of Palaeozoic tetrapod interrelationships (Clack 1994; Smithson 1994; Lombard \& Bolt 1995).

Among the least ambiguous features linking Caerorhachis to basal reptiliomorphs are: subcircular depression on basal plate of parasphenoid with thick peripheral rim; enlarged U-shaped pleurocentra; reduced dorsal iliac blade; L-shaped tarsal intermedium. The depression on the basal plate of the parasphenoid appears occasionally in reptiliomorphs. Importantly, the development of pronounced posterolateral ridges on the parasphenoid (often ending in stout basal tubera; see Clack \&
Holmes 1988) may represent an additional amniote character, given their presence in 'anthracosaurs' (e.g. Carroll 1970; Panchen 1985; Smithson 1985b; Holmes 1984, 1989; Clack 1987b, 1998a), seymouriamorphs (e.g. White 1939; Klembara 1997), diadectomorphs (Berman et al. 1998), and various primitive crown-group amniotes (e.g. Reisz 1981). However, their presence in Caerorhachis is dubious. The gastrocentrous (enlarged pleurocentrum) condition of the vertebral centra is not unique to reptiliomorphs, because some microsaurs and dissorophoid temnospondyls reveal similar patterns. Interestingly, in the case of Paton et al.'s (1999) analysis microsaurs appear as stem-group amniotes; their gastrocentrous condition 
is thus congruent with that of 'anthracosaurs' and crown-group amniotes. U-shaped pleurocentra occur in certain 'anthracosaurs' (e.g. Carroll 1970; Smithson 1985b), but no clear polarity is evident in the transformation of pleurocentra when other 'anthracosaurs' (e.g. Holmes 1989), microsaurs and crowngroup amniotes are considered (see Smithson et al. 1994). Reptiliomorphs show different degrees of reduction of the dorsal iliac blade, the presence of which is a primitive tetrapod feature (see Coates 1996). The ilium of Caerorhachis is surprisingly reminiscent of that of various basal amniotes (e.g. Carroll $\&$ Baird 1972) in possessing a reduced dorsal blade. It is unlike the ilia of e.g. Archeria and Proterogyrinus, in which the dorsal blade is pronounced. The morphology of the tarsal intermedium was discussed in detail by Lebedev \& Coates (1995) and Coates (1996), who used it to link reptiliomorph ancestry to such early taxa as Tulerpeton, implying a late Devonian time of divergence for the evolutionary split between lissamphibians and amniotes (but see Clack 1998b, and Paton et al. 1999). It is also observed in various 'anthracosaurs' (e.g. Holmes 1984, 1989), diadectomorphs and certain captorhinid and protorothyridid captorhinomorphs (e.g. Sumida 1997), as well as in some basal synapsids and diapsids (e.g. Reisz 1981), but not in seymouriamorphs (e.g. Berman et al. 2000).

Possible additional amniote characters of Caerorhachis, although not uniquely derived, include: curved trunk ribs; cervical ribs straight, morphologically distinct from trunk ribs and with flattened distal ends; rearmost part of mesial lamina of splenial closer to anterior margin of adductor fossa than to lower jaw symphysis; transverse ridge sweeping from lateral surface to ventral edge of posterior iliac process. Dorsoventrally curved trunk ribs are certainly primitive for amniotes (e.g. Milner 1988, 1990; Coates 1996). However, they are known to occur in other groups (e.g. some microsaurs and nectrideans, and large temnospondyls). Marked morphological difference between cervical/pectoral ribs and trunk ribs is also observed in some microsaurs (e.g. the genera Micraroter, Pantylus, Pelodosotis and Saxonerpeton, Carroll \& Gaskill 1978), and nectrideans (e.g. Diplocaulus, Bossy \& Milner 1998). The rearward extension of the mesial lamina of the splenial, closer to the anterior margin of the adductor fossa than to the anterior end of the mandible, is found in baphetids, 'anthracosaurs', seymouriamorphs, diadectomorphs and amniotes s.s. (White 1939; Bystrow 1944; Romer 1956; Beaumont 1977; Holmes 1984, 1989; Smithson 1986; Clack 1987b; Klembara 1997; Ahlberg \& Clack 1998). It is also present in some microsaurs (e.g. Euryodus, Microbrachis, Pantylus; Carroll \& Gaskill 1978), and in all nectrideans in which the mesial aspect of the lower jaw is known in sufficient detail (e.g. Sauropleura, Batrachiderpeton, Diploceraspis; Bossy $\&$ Milner 1998). Importantly, this character is not linked to the occurrence of a postsplenial, or to the relative length of the adductor fossa. Finally, a transverse ridge sweeping from the lateral surface to the ventral margin of the posterior iliac process occurs in 'anthracosaurs' (e.g. Carroll 1970; Holmes 1984, 1989; Smithson 1985b), seymouriamorphs (e.g. White 1939; Klembara \& Bartik 2000), diadectomorphs (e.g. Romer 1956; Berman \& Sumida 1990; Berman et al. 1998), and (sporadically) basal amniotes (e.g. Romer 1956; Vaughn 1955). The temnospondyls Eryops and Dendrerpeton possess faint iliac ridges (Romer 1922; Holmes et al. 1998), although these are almost certainly examples of convergence with 'anthracosaurs'. In Dendrerpeton, the course and orientation of the iliac ridge resemble closely those of Caerorhachis, although the ridge of Dendrerpeton is not accompanied by muscle scars. The iliac ridge is modified in seymouriamorphs and diadectomorphs, where it delimits a lateral iliac shelf (e.g. Romer 1956; Klembara \& Bartik 2000). In some synapsids (e.g. Edapho- saurus, see Romer 1956), a short ridge merges with the dorsal surface of the supra-acetabular buttress. Vaughn (1955) draws a faint line, corresponding in position to the 'anthracosaur' ridge, on the ilium of the early amniote Araeoscelis.

Other characters of Caerorhachis are of dubious polarity or too poorly known to be used in a character analysis. Thus, the size difference between vomerine and palatine/ectopterygoid fangs is also observed in other tetrapods (e.g. Edops, Eryops, Phonerpeton, Dendrerpeton, etc.; Romer 1947; Dilkes 1990), and may be growth-related. With regard to the shape of the prefrontal, the validity of this character rests on the difficult, and admittedly very tentative interpretation of a highly weathered skull roof element. If correctly interpreted, however, it suggests an additional baphetid-like feature in Caerorhachis, together with shape and position of the choanae, and morphology of the anterior palatal region (see 'Description' above).

Concerning the palatal vacuities, these are widely distributed among Palaeozoic tetrapods (e.g. temnospondyls, colosteids, some microsaurs and nectrideans, and various 'anthracosaurs'). The definition of vacuities adopted here follows Milner \& Sequeira (1994). It is based on their degree of curvature and relative width, but takes into account also the triradiate shape of the pterygoids and the elongate, parallelsided cultriform process of the parasphenoid. None of these conditions is seen in Caerorhachis (although the cultriform process is poorly preserved). However, one or more of them characterise most temnospondyls, some nectrideans, and at least one microsaur (Carroll \& Gaskill 1978; Milner 1993b; Bossy \& Milner 1998). Thus, the simple presence of vacuities may be of little significance with regard to the supposed ternnospondyl affinities of Caerorhachis (contra Holmes 2000).

Finally, it is hoped that our reassessment of Caerorhachis makes this taxon a suitable candidate for inclusion in future, comprehensive cladistic analyses of early tetrapod interrelationships.

\section{Acknowledgements}

Drs Anne Warren (La Trobe University, Melbourne) and Adam Yates (University of Bristol) provided stimulating and constructive criticism. Dr Andrew Smith (The Natural History Museum, London) offered helpful editorial comments. Professor Robert Carroll (McGill University, Montreal) and Dr Angela Milner (The Natural History Museum, London) lent us casts of Caerorhachis. Drs Jenny Clack (University of Cambridge) and Tim Smithson (Aylesbury College, Buckinghamshire) exchanged much useful information. Dr Clack kindly supplied a copy of the Casineria matrix and a prepublication draft of her Eucritta redescription. This work is funded by BBSRC Advanced Research Fellowship no. 31/ AF/13042 awarded to Michael I. Coates.

\section{Abbreviations used in figures}

a.ac.n-anterior acetabular notch

ac_-acetabulum

add.cr-adductor crest

ad.fo-adductor fossa

ANG - angular

ant.COR - anterior coronoid

ant.M.f-anterior Meckelian foramen

ART_articular

$c_{1}$ - centrale 1 
$\mathrm{c}_{2}$ centrale $_{2}$

$\mathrm{c}_{3}-$ centrale $_{3}$

ch-choana

DE-dentary

dib-dorsal iliac blade

ECPT-ectopterygoid

FBL-fibulare

FBL.fa-fibulare facet

fi.fa-fibular facet

FR - frontal

fun.exc - funnel-shaped excavation (posterolateral wall of choana)

hs-haemal spine

ic-intercentrum

ico.gr - intercondylar groove

IL-ilium

INT-intermedium

INT.fa.f - facet for intermedium on fibula

INT.fa.t - facet for intermedium on tibia

in.tr-internal trochanter

ISCH - ischium

IT-intertemporal

MAX - maxilla

mes.lam.ANG - mesial lamina of angular

mes.lam.POSPL — mesial lamina of postsplenial

mes.lam. SPL - mesial lamina of splenial

mid.COR - middle coronoid

mid.M.f - middle Meckelian foramen

msm - mesial shelf of maxilla

mtt - metatarsal

$\mathrm{NA}$ - nasal

n.ar-neural arch

PA-parietal

p.ac.n-posterior acetabular notch

PAL - palatine

PAS - parasphenoid

pc - pleurocentrum

pdip_posterodorsal iliac process

ph-phalanx

PO - postorbital

POFR - postfrontal

POSPL-postsplenial

post.COR - posterior coronoid

post.M.f-posterior Meckelian foramen

PP_postparietal

PREART - prearticular

PSYM - parasymphysial plate

PT-pterygoid

PU-pubis

QJ-quadratojugal

$\mathrm{rb}$-round bosses

r.r-rugose ridge for flexor muscle attachment on tibia

sab-supra-acetabular buttress

SPL-splenial

SQ - squamosal

ST-supratemporal

SURANG - surangular

sur.cre - surangular crest

sym-symphysis

TA - tabular

$\mathrm{TBL}+\mathrm{c}_{4}$ - tibiale + centrale $_{4}$

TBL.fa-tibiale facet

ti.fa-tibial facet

tr.pel.r - transverse pelvic ridge

tsl-tarsal

tu.istr-tuberosity for insertion of ischiotrochantericus muscle

VOM-vomer

\section{Appendix. Coding for Caerorhachis in different data sets}

Carroll 1995

1???? ??1?? ??01? ???11 00000001121 1??00 $0102011 ? 10000 ? 1$ ?21?? ???2? ?1001 300?0 011?? ????? ??121 ???1? ????3 ?201? $210101(12) 012$ 1?1(12)? ????? ????? ??(12)11 (012)???? ????? ????? (012)??2?????1 ???11 11?11 1111(12) 11112 (12)411? 1111

\section{Coates 1996}

?2??? 001?1(12)(12)12?????1 0??11 11?(12)1 0(12)02???1?0 1?1??

?11?1 1???? 10?1? 1?1?1 ??10? 1???0

\section{Clack 1998a}

??200 ????? ??0?? ????? ?00?0 0???? ??2(01)0 00??1 10??? 01211

$1 ? ? ? 0111001110$ ? 01111 ?01?? ????? ?111? 1?1

\section{Clack 1998b}

?1??1 ??00? ????? ????? ????0 0(01)0?? ????2 (01)?000 ???11 0??11 211011011100111010 ?? 01111 ?201? ????? ?011? ????? ?0??? ??11000?111

\section{Ahlberg \& Clack 1998}

$011010113111111 ? ? ? 11011010000101010 ? 001000111 ? ? ? 01$

\section{Laurin 1998a}

(02)?20? 110?? (01)0000 000?000000?00?? 200000202010001 001000010001000 ???0(23) 1100? 1??0? ???20 0000000100 01000 01??? ?001? ????? 1?101 1110(01) 00??? ????0 ????? ??01? (23)?1(12)?(12)0002 10221

Paton, Smithson \& Clack 1999

1???? ?00?? ????? ?1121 10000 ?0??? (01)???2 (01)??00 ??0?? ?1011 $0011101 ? ? 001111$ ?201? ????? ?0?01 ????? 0???? ?0??? 001?? 11(01)(01)(456) 00??1 1

\section{References}

Ahlberg, P .E. 1998. Postcranial stem tetrapod remains from the Devonian of Scat Craig, Morayshire, Scotland. Zoological Journal of the Linnean Society 122, 99-141.

Ahlberg. P. E. \& Clack, J. A. 1998. Lower jaws, lower tetrapodsa review based on the Devonian genus Acanthostega. Transactions of the Royal Society of Edinburgh: Earth Sciences 89, 11-46.

Ahlberg, P. E. \& Milner, A. R. 1994. The origin and early diversification of tetrapods. Nature 368, 507-14.

Andrews, S. M. \& Brand, P. J. 1991. Postscript: confounded ironstones in the Limestone Coal Group of Loanhead, Midlothian. Transactions of the Royal Society of Edinburgh: Earth Sciences 82, 273-5.

Beaumont, E. H. 1977. Cranial morphology of the Loxommatidae (Amphibia: Labyrinthodontia). Philosophical Transactions of the Royal Society of London B280, 29-101.

Beaumont, E. H. \& Smithson, T. R. 1998. The cranial morphology and relationships of the aberrant Carboniferous amphibian Spathicephalus mirus Watson. Zoological Journal of the Linnean Society 122, 187-209.

Berman, D. S. 2000. Origin and early evolution of the amniote occiput. Journal of Paleontology 74, 938-56.

Berman, D. S., Reisz, R. R.\& Eberth, D. A. 1985. Ecolsonia cutlerensis, an early Permian dissorophid amphibian from the Cutler Formation of north-central New Mexico. Circular of the New Mexico Bureau of Mines and Mineral Resources 191, 1-31.

Berman, D. S., Sumida, S. S. \& Martens, T. 1998. Diadectes (Diadectomorpha: Diadectidae) from the early Permian of central Germany, with description of a new species. Annals of Carnegie Museum 67, $53-93$

Berman, D. S., Henrici, A. C., Sumida, S. S. \& Martens, T. 2000 Redescription of Seymouria sanjuanensis (Seymouriamorpha) from the Lower Permian of Germany based on complete, mature specimens with a discussion of paleoecology of the Bromacker locality assemblage. Journal of Vertebrate Paleontology 20, 25368. 
Berman, D. S. \& Sumida, S. S. 1990. A new species of Limnoscelis (Amphibia, Diadectomorpha) from the late Pennsylvanian Sangre de Cristo Formation of central Colorado. Annals of Carnegie Museum 59, 303-41.

Bolt, J. R. 1969. Lissamphibian origins: possible protolissamphibian from the Lower Permian of Oklahoma. Science 166, 888-91.

Bolt, J. R. 1979. Amphibamus grandiceps as a juvenile dissorophid: evidence and implications. In Nitecki, M. H. (ed.). Mazon Creek Fossils, 529-63. New York: Academic Press.

Bolt, J. R. 1991. Lissamphibian origins. In Schultze, H.-P. \& Trueb, L. (eds) Origins of the higher groups of tetrapods: controversy and consensus, 194-222. Ithaca: Cornell University Press.

Bossy, A. K. \& Milner, A. C. 1998. Order Nectridea Miall, 1875. In Carroll, R. L., Bossy, K. A., Milner, A. C., Andrews, S. M. \& Wellstead, C. F. (eds) Teil 1, Lepospondyli. Handbuch der Paläoherpetologie, 73-212. Munich: Pfeil.

Busbey, A. B. 1995. The structural consequences of skull flattening in crocodilians. In Thomason, J. J. (ed.) Functional morphology in vertebrate paleontology, 173-92. Cambridge: Cambridge University Press.

Bystrow, A. P. 1944. On Kotlassia prima (Amalitsky). Bulletin of the Geological Society of America 55, 379-416.

Carroll. R. L. 1970. The ancestry of reptiles. Philosophical Transactions of the Royal Society of London B257, 267-308.

Carroll, R. L. 1988. Vertebrate paleontology and evolution. New York: Freeman.

Carroll, R. L. 1991. Batropetes from the Lower Permian of Europea microsaur, not a reptile. Journal of Vertebrate Paleontology 11, $229-42$.

Carroll, R. L. 1995. Problems of the phylogenetic analysis of Paleozoic choanates. In Arsenault, M. Lelièvre, H. \& Janvier, P. (eds) Studies on early vertebrates: (VIIth International Symposium, Parc de Miguasha, Quebec). Bulletin du Museum National d'Histoire Naturelle, Paris (Ser. 4) 17 (C), 38-445.

Carroll. R. L. 1996. Elongate early tetrapods: why 'Lizzie' had little limbs. In Milner, A. R. (ed.) Studies on Carboniferous and Permian vertebrates. Special Papers in Palaeontology 52,139-48.

Carroll, R. L., Bybee. P. \& Tidwell, W. D. 1991. The oldest microsaur (Amphibia). Journal of Paleontology 65, 314-22.

Carroll, R. L., Bossy, K. A., Milner, A. C., Andrews, S. M. \& Wellstead, C. F. 1998. Teil 1, Lepospondyli. Handbuch der Palaoherpetologie. Munich: Pfeil.

Carroll, R. L. \& Baird, D. 1972. Carboniferous stem-reptiles of the Family Romeriidae. Bulletin of the Museum of Comparative Zoology 143, 321-64.

Carroll, R. L. \& Gaskill. P. 1978. The Order Microsauria. Memoirs of the American Philosophical Society 126, 1-211.

Clack, J. A. 1987a. Two new specimens of Anthracosaurus (Amphibia: Anthracosauria) from the Northumberland Coal Measures. Palaeontology 30, 15-26.

Clack. J. A. 1987b. Pholiderpeton scutigerum Huxley, an amphibian from the Yorkshire Coal Measures. Philosophical Transactions of the Royal Society of London B318, 1-107.

Clack, J. A. 1994. Silvanerpeton miripedes, a new anthracosauroid from the Viséan of East Kirkton, West Lothian, Scotland. Transactions of the Royal Society of Edinburgh: Earth Sciences 84, 369-76.

Clack, J. A. 1998a. The Scottish Carboniferous tetrapod Crassigyrinus scotcus (Lydekker) - cranial anatomy and relationships. Transactions of the Royal Society of Edinburgh: Earth Sciences $\mathbf{8 8}$ (for 1997), $127-42$.

Clack, J. A. 1998b. A new Early Carboniferous tetrapod with a mélange of crown-group characters. Nature 394, 66-9.

Clack, J. A. 2001. Eucritta melanolimnetes from the Early Carboniferous of Scotland, a stem tetrapod showing a mosaic of characteristics. Transactions of the Royal Society of Edinburgh: Earth Sciences 92, 75-95.

Clack, J. A. \& Holmes, R. 1988. The braincase of the anthracosaur Archeria crassidisca with comments on the interrelationships of primitive tetrapods. Palaeontology 31, 85-107.

Coates, M. I. 1996. The Devonian tetrapod Acanthostega gunnari Jarvik: postcranial anatomy, basal tetrapod interrelationships and patterns of skeletal evolution. Transactions of the Royal Society of Edinburgh: Earth Sciences 87, 363-421.

Coates, M. I., Milner, A. R. \& Ruta, M. 2000. Early tetrapod evolution. Trends in Ecology and Evolution 15, 327-8.

Daeschler, E. B. 2000. Early tetrapod jaws from the late Devonian of Pennsylvania, USA. Journal of Paleontology 74, 301-8.

Daeschler, E. B., Shubin, N., Thomson, K. S. \& Amaral, W. W. 1994. A Devonian tetrapod from North America. Science 265, 63942.
Dilkes, D. W. 1990. A new trematopsid amphibian (Temnospondyli: Dissorophoidea) from the Lower Permian of Texas. Journal of Vertebrate Paleontology 10, 222-43.

Fox, R. C., Campbell, K. S. W., Barwick, R. E. \& Long, J. A. 1995. A new osteolepiform fish from the Lower Carboniferous Raymond Formation, Drummond Basin, Queensland. Memoirs of the Queensland Museum 38, 97-221.

Gardiner, B. G. 1984. The relationships of the palaeoniscid fishes, a review based on new specimens of Mimia and Moythomasia from the Upper Devonian of Western Australia. Bulletin of the British Museum (Natural History): Geology Series 37, 173428.

Gauthier, J. A., Kluge, A. G. \& Rowe, T. 1988. The early evolution of the Amniota. In Benton, M. J. (ed.) The phylogeny and classification of the tetrapods, 1: Amphibians, Reptiles, Birds, 103-55. Oxford: Clarendon Press.

Godfrey, S. J. 1989. The postcranial skeletal anatomy of the Carboniferous tetrapod Greererpeton burkemorani. Philosophical Transactions of the Royal Society of London B323, 75-133.

Godfrey, S. J., Fiorillo, A. R. \& Carroll, R. L. 1987. A newly discovered skull of the temnospondyl amphibian Dendrerpeton acadianum Owen. Canadian Journal of Earth Sciences 24, 796-805.

Goodrich, E. S. 1930. Studies on the structure and development of vertebrates. London: Macmillan \& Co.

Harland, W. B., Armstrong, R. L., Cox, A. V., Craig, L. E., Smith, A. G. \& Smith, D. G. 1989. A geologic time scale 1989. Cambridge: Cambridge University Press.

Heaton, M. J. 1979. Cranial anatomy of primitive captorhinid reptiles from the Late Pennsylvanian and Early Permian, Oklahoma and Texas. Bulletin of the Oklahoma Geogical Suevey 127, 1-80.

Heaton, M. J. 1980. The Cotylosauria: a reconsideration of a group of archaic tetrapods. In Panchen, A. L. (ed.) The terrestrial environment and the origin of land vertebrates, 497-551. London: Academic Press.

Holmes, R. B. 1984. The Carboniferous amphibian Proterogyrinus scheele $i$ Romer, and the early evolution of tetrapods. Philosophical Transactions of the Royal Society of London B306, 431-527.

Holmes, R. B. 1989. The skull and axial skeleton of the Lower Permian anthracosauroid amphibian Archeria crassidisca Cope. Palaeontographica 207, 161-206.

Holmes, R. B. 2000. Palaeozoic temnospondyls. In Heatwole, H. E. \& Carroll, R. L. (eds) Amphibian Biology 4: Palaeontology, 1081-120. Chipping Norton: Surrey Beatty \& Sons.

Holmes, R. B., Carroll, R. L. \& Reisz, R. R. 1998. The first articulated skeleton of Dendrerpeton acadianum (Temnospondyli, Dendrerpetontidae) from the lower Pennsylvanian locality of Joggins, Nova Scotia, and a review of its relationships. Journal of Vertebrate Paleontology 18, 64-79.

Holmes, R. B. \& Carroll, R. L. 1977. A temnospondyl amphibian from the Mississippian of Scotland. Bulletin of the Museum of Comparative Zoology 147, 489-511.

Hook, R. W. 1983. Colosteus scutellatus (Newberry), a primitive temnospondyl amphibian from the Middle Pennsylvanian of Linton, Ohio. American Museum Novitates 2770, 1-41.

Jarvik, E. 1980. Basic structure and evolution of vertebrates 1, 1-591. London and New York: Academic Press.

Jarvik, E. 1996. The Devonian tetrapod Ichthyostega. Fossils \& Strata 40, $1-206$.

Klembara, J. 1997. The cranial anatomy of Discosauriscus Kuhn, a seymouriamorph tetrapod from the Lower Permian of the Boskovice Furrow (Czech Republic). Philosophical Transactions of the Royal Society of London B352, 257-302.

Klembara, J. \& Bartik, I. 2000. The postcranial skeleton of Discosauriscus Kuhn, a seymouriamorph tetrapod from the Lower Permian of the Boskovice Furrow (Czech Republic). Transactions of the Royal Society of Edinburgh: Earth Sciences 90 (for 1999), 287-316.

Laurin, M. 1998a. The importance of global parsimony and historical bias in understanding tetrapod evolution. Part I. Systematics, middle ear evolution, and jaw suspension. Annales des Sciences Naturelles, Zoologie 1, 1-42.

Laurin, M. 1998b. The importance of global parsimony and historical bias in understanding tetrapod evolution. Part II. Vertebral centrum, costal ventilation, and paedomorphosis. Annales des Sciences Naturelles, Zoologie 19, 99-114.

Laurin, M. 1998c. A reevaluation of the origin of pentadactyly. Evolution 52, 1476-82.

Laurin, M., Girondot, M. \& de Ricqlès, A. 2000a. Early tetrapod evolution. Trends in Ecology and Evolution 15, 118-23.

Laurin, M., Girondot, M. \& de Ricqles̀, A. 2000b. Reply. Trends in Ecology and Evolution 15, 328. 
Laurin, M. \& Reisz, R. R. 1997. A new perspective on tetrapod phylogeny. In Sumida, S. S. \& Martin, K. L. M. (eds) Amniote origins: completing the transition to land, 9-59. London: Academic Press.

Laurin, M. \& Reisz, R. R. 1999. A new study of Solenodonsaurus janenschi, and a reconsideration of amniote origins and stegocephalian evolution. Canadian Journal of Earth Sciences 36, 1239-55.

Lebedev, O. A. \& Clack, J. A. 1993. Upper Devonian tetrapods from Andreyevka, Tula region, Russia. Palaeontology 36, 721-34.

Lebedev, O. A. \& Coates, M. I. 1995. The postcranial skeleton of the Devonian tetrapod Tulerpeton curtum Lebedev. Zoological Journal of the Linnean Society 114, 307-48.

Lombard, R. E. \& Bolt, J. R. 1995. A new primitive tetrapod Whatcheeria deltae from the Lower Carboniferous of Iowa. Palaeontology 38, 471-94.

Long, J. A., Barwick, R. E. \& Campbell, K. S. W. 1997. Osteology and functional morphology of the osteolepiform fish Gogonasus andrewsae Long, 1985, from the Upper Devonian Gogo Formation, Western Australia. Records of the Western Australian Museum, Supplement 53, 1-89.

Maddison, W. P. \& Maddison, D. R. 1992. MacClade: Analysis of phylogeny and character evolution. Version 3.0.1. Sunderland, Massachusetts: Sinauer Associates. Milner, A. C. 1980. A review of the Nectridea (Amphibia). In Panchen, A. L. (ed.) The terrestrial environment and the origin of land vertebrates, 377-405. London: Academic Press.

Milner, A. C. \& Lindsay, W. 1998. Postcranial remains of Baphetes and their bearing on the relationships of the Baphetidae (= Loxommatidae). Zoological Journal of the Linnean Society 122, 211-35.

Milner, A. R. 1980. The temnospondyl amphibian Dendrerpeton from the Upper Carboniferous of Ireland. Palaeontology 23, $125-41$.

Milner, A. R. 1988. The relationships and origin of living amphibians. In Benton, M. J. (ed.) The phylogeny and classification of the tetrapods, 1: Amphibians, Reptiles, Birds, 59-102. Oxford: Clarendon Press.

Milner, A. R. 1990. The radiations of temnospondyl amphibians. In Taylor, P. D. \& Larwood, G. P (eds) Major evolutionary radiations, 321-49. Oxford: Clarendon Press.

Milner, A. R. 1993a. Amphibian-grade Tetrapoda. In Benton, M. J. (ed.) The Fossil Record 2, 665-79. London: Chapman \& Hall.

Milner, A. R. 1993b. The Paleozoic relatives of lissamphibians. Herpetological Monographs 7, 8-27.

Milner, A. R., Smithson, T. R., Milner, A. C., Coates, M. I. \& Rolfe, W. D. I. 1986. The search for early tetrapods. Modern Geology 10, $1-28$.

Milner, A. R. \& Sequeira, S. E. K. 1994. The temnospondyl amphibians from the Viséan of East Kirkton, West Lothian, Scotland. Transactions of the Royal Society of Edinburgh: Earth Sciences $\mathbf{8 4}$ (for 1993), 331-61.

Milner, A. R. \& Sequeira, S. E. K. 1998. A cochleosaurid temnospondyl amphibian from the 6 Middle Pennsylvanian of Linton, Ohio, U.S.A. Zoological Journal of the Linnean Society 122, 261-90.

Moulton, J. M. 1974. A description of the vertebral column of Eryops based on the notes and drawings of A. S. Romer. Breviora 428, $1-44$.

Panchen, A. L. 1973. On Crassigyrinus scoticus Watson, a primitive amphibian from the Lower Carboniferous of Scotland. Palaeontology 16, 179-93.

Panchen, A. L. 1977. On Anthracosaurus russelli Huxley (Amphibia: Labyrinthodontia) and the family Anthracosauridae. Philosophical Transactions of the Royal Society of London B279, 447512.

Panchen, A. L. 1980. The origin and relationships of the anthracosaur Amphibia from the late Palaeozoic. In Panchen, A. L. (ed.) The terrestrial environment and the origin of land vertebrates, 319-50. London: Academic Press.

Panchen, A. L. 1985. On the amphibian Crassigyrinus scoticus Watson from the Carboniferous of Scotland. Philosophical Transactions of the Royal Society of London B309, 505-68.

Panchen, A. L. \& Smithson, T. R. 1987. Character diagnosis, fossils, and the origin of tetrapods. Biological Reviews 62, 341-438.

Panchen, A. L. \& Smithson, T. R. 1988. The relationships of early tetrapods. In Benton, M. J. (ed.) The phylogeny and classification of the tetrapods 1, 1-32. Oxford: Clarendon Press.

Panchen, A. L. \& Smithson, T. R. 1990. The pelvic girdle and hind limb of Crassigyrinus scoticus (Lydekker) from the Scottish Carboniferous and the origin of the tetrapod pelvic skeleton. Transactions of the Royal Society of Edinburgh: Earth Sciences 81, 31-44.
Paton, R. L., Smithson, T. R. \& Clack, J. A. 1999. An amniote-like skeleton from the Early Carboniferous of Scotland. Nature 398, 508-13.

Pough, F. H., Andrews, R. M., Cadle, J. E., Crump, M. L., Savitzky, A. H. \& Wells, K. D 2000. Herpetology, 2nd edn. Upper Saddle River: Prentice Hall.

Reisz, R. R. 1981. A diapsid reptile from the Permian of Kansas. Special Publications of the Museum of Natural History 7, 1-74.

Romer, A. S. 1922. The locomotor apparatus of certain primitive and mammal-like reptiles. Bulletin of the American Museum of Natural History 46, 517-606.

Romer, A. S. 1947. Review of the Labyrinthodontia. Bulletin of the Museum of Comparative Zoology 99, 1-368.

Romer, A. S. 1956. Osteology of the reptiles. Chicago: University of Chicago Press.

Romer, A. S. 1957. The appendicular skeleton of the Permian embolomerous amphibian Archeria. Contributions of the Museum of Geology of the University of Michigan 13, 103-59.

Romer, A. S. 1966. Vertebrate paleontology. Chicago: University of Chicago Press.

Romer, A. S. \& Parsons, T. S. 1977. The vertebrate body, 5th edn. Philadelphia: W. B. Saunders.

Romer, A. S. \& Witter, R. V. 1942. Edops, a primitive rhachitomous amphibian from the Texas red beds. Journal of Geology 50, 925-60.

Säve-Söderbergh, G. 1934. Some points of view concerning the evolution of the vertebrates and the classification of this group. Arkiv für Zoologi 26, 1-20.

Schoch, R. R. \& Milner, A. R. 2000. Teil 3B, Stereospondyli. Handbuch der Paläoherpetologie. Munich: Pfeil.

Sequeira, S. E. K. 1996. A cochleosaurid amphibian from the Upper Carboniferous of Ireland. In Milner, A. R. (ed.) Studies on Carboniferous and Permian vertebrates. Special Papers in Palaeontology 52, 65-80.

Sequeira, S. E. K \& Milner, A. R. 1993. The temnospondyl amphibian Capetus from the Upper Carboniferous of $\mathrm{Ny}^{\prime} \mathrm{r}^{\circ}$ any, Czech Republic. Palaeontology 36, 657-80.

Smithson, T. R. 1980. An early tetrapod fauna from the Namurian of Scotland. In Panchen, A. L. (ed.) The terrestrial environment and the origin of land vertebrates, 407-38. London: Academic Press.

Smithson, T. R. 1982. The cranial morphology of Greererpeton burkemorani Romer (Amphibia: Temnospondyli). Zoological Journal of the Linnean Society 76, 29-90.

Smithson, T. R. 1985a. Scottish Carboniferous amphibian localities. Scottish Journal of Geology 21, 123-42.

Smithson, T. R. 1985b. The morphology and relationships of the Carboniferous amphibian Eoherpeton watsoni Panchen. Zoological Journal of the Linnean Society 85, 317-410.

Smithson, T. R. 1986. A new anthracosaur amphibian from the Carboniferous of Scotland. Palaeontology 29, 603-28.

Smithson, T. R. 1994. Eldeceeon rolfei, a new reptiliomorph from the Viséan of East Kirkton, West Lothian, Scotland. Transactions of the Royal Society of Edinburgh: Earth Sciences 84 (for 1993), 377-82.

Smithson, T. R., Carroll, R. L., Panchen, A. L. \& Andrews, S. M. 1994 Westlothiana lizziae from the Viséan of East Kirkton, West Lothian, Scotland, and the amniote stem. Transactions of the Royal Society of Edinburgh: Earth Sciences 84 (for 1993), 383 412 .

Sullivan, C., Reisz, R. R. \& May, W. J. 2000. Large dissorophoid skeletal elements from the Lower Permian Richards Spur fissures, Oklahoma, and their paleoecological implications. Journal of Vertebrate Paleontology 20, 456-61.

Sumida, S. S. 1997. Locomotor features of taxa spanning the origin of amniotes. In Sumida, S. S. \& Martin, K. L. M. (eds) Amniote origins: completing the transition to land, 353-98. London: Academic Press.

Sumida, S. S., Lombard, R. E. \& Berman, D. S. 1992. Morphology of the atlas-axis complex of the late Palaeozoic tetrapod suborders Diadectomorpha and Seymouriamorpha. Philosophical Transactions of the Royal Society of London 336, 259-73.

Swofford, D. L. 1993. PAUP: Phylogenetic analysis using parsimony. Version 3.1.1. Champaign, Illinois: Illinois Natural History Survey.

Swofford, D. L. 2000. PAUP*: Phylogenetic analysis using parsimony (*and other methods). Version 4.0b4a. Sunderland, Massachusetts: Sinauer Associates.

Vaughn, P. P. 1955. The Permian reptile Araeoscelis restudied. Bulletin of the Museum of Comparative Zoology 113, 305-467. 
Wellstead, C. F. 1991. Taxonomic revision of the Lysorophia, PermoCarboniferous lepospondyl amphibians. Bulletin of the American Museum of Natural History 209, 1-90.

White, T. E. 1939. Osteology of Seymouria baylorensis (Broili). Bulletin of the Museum of Comparative Zoology 85, 325-409.

Williston, S. W. 1910. Cacops, Desmospondylus. new genera of Permian vertebrates. Bulletin of the Geological Society of America 21, 24984.

Yates, A. M. \& Warren, A. A. 2000. The phylogeny of the 'higher' temnospondyls (Vertebrata: Choanata) and its implications for the monophyly and origins of the Stereospondyli. Zoological Journal of the Linnean Society 128, 77-121.

MARCELLO RUTA* and MICHAEL I. COATES*, Department of Biology, University College London, Gower Street, London WC1E 6HT, UK.

*Present address: Department of Organismal Biology and Anatomy, University of Chicago, 1027 East 57th Street, Chicago, IL 60637, U.S.A.

e-mail:mruta@midway.uchicago.edu; mcoates@midway.uchicago.edu

ANDREW R. MILNER, Department of Biology, Birkbeck College, Malet Street, London

WC1E 7HX, UK. e-mail: a.milner@biology.bbk.ac.uk

MS received 15 December 2000. Accepted for publication 29 June 2001. 